\title{
New Insights in Prime Roles of Indian Subcontinent in Nurture of Global Heating and Hurricanes with Review of the Only Window for Their Calamities Control
}

\author{
Malik Muhammad Nazeer \\ Islamabad, Pakistan \\ Email:naz188nbsg@gmail.com
}

How to cite this paper: Nazeer, M.M. (2020) New Insights in Prime Roles of Indian Subcontinent in Nurture of Global Heating and Hurricanes with Review of the Only Window for Their Calamities Control. Open Access Library Journal, 7: e6424. https://doi.org/10.4236/oalib.1106424

Received: May 14, 2020

Accepted: August 18, 2020

Published: August 21, 2020

Copyright $\odot 2020$ by author(s) and Open Access Library Inc.

This work is licensed under the Creative Commons Attribution International License (CC BY 4.0).

http://creativecommons.org/licenses/by/4.0/

\section{Open Access}

\begin{abstract}
A new paradigm of Indian Subcontinent prime roles in governing Global Heat contents and Temperature (GHT) and North Atlantic Hurricanes $(\mathrm{NAH})$ etc. is presented in this work. It is established here that huge GHT rise rate of $16.48 \mathrm{ZJ}$ (Zeta Joules $=10^{21}$ Joules) after 1965/70 from about $2 \mathrm{ZJ}$ before 1960 is due to an un-natural, un-scientific and un-logical human reversal of one of these roles. Henceforth, almost all the Global Hazards and Calamities are being continuously nourished by this huge continuous GHT rise, which is being continuously pushed up and up by Indian blocking of Freon feed to Divinely established Global Air Conditioner (GAC). This Freon was, the water irrigating South-eastern Pakistan by its eastern three rivers diverted to India under Indus Basin Water Treaty 1960 (IBWT), fully functional since 1970. A few terrible aftermaths of this activity are pointed out for some vision of the situation of its global gravity along with revisit and review of assumptions and estimates of capabilities of the only window open for its human control. The reversal of IBWT will slow down the GHT growth by $14.235 \mathrm{ZJ}$ (80\%), but for its complete blockage and the drainage of its already 50 years heaped terrible GHC since 1970, the vitality of optimal mobilization of irrigation of other two parts of Pakistan irrigation system with estimated 9.893 ZJ \& $15.78 \mathrm{ZJ}$ Global heat dissipation potentials is elaborated in this wok. Immediate intervention and optimal mobilization of all resources are needed to regain 1960 climate status in minimum 42 years (earliest by 2074) and avoid big bang banging by its nurtured GHT continuous growth. At the end, some recommendations are presented for safe existence of life on this Globe by its calamities control through this strategy.
\end{abstract}




\section{Subject Areas}

Environmental Sciences, Hydrology

\section{Keywords}

Freon of Global Air Conditioner, 100 Years Frequency of North Atlantic

Hurricanes, Indian Air Wheels and Monsoons, Irrigation System of Pakistan, Global Heat Transmission to Troposphere, Indus Basin Water Treaty

\section{Introduction}

In the last half century, the Global environment status initially named as "Climate Change" was generally agreed to be renamed as "Global Warming" and now "Global Heating" is a more accurate term being used by climate scientists and organizations from the UN to the Met Office. Some are even using stronger language to describe the situation by "Climate Emergency, crises or breakdown". It has taken a very sharp upward turn with much increased speed after 1965, as can be seen in all the graphs on GHC and Global Average Temperature and now it seems that this is heading towards "Global Cooking, Roasting or Burning". In statistics, the rate of annual rise of Global Heat Contents (GHC) has become 16.48 ZJ (Zeta Joules = 10 ${ }^{21}$ Joules) after 1971/1972 [1] [2] [3] [4] from about less than 2 ZJ before 1960. This has resulted in extremely huge growth in almost all hazardous events, disasters and calamities [5] after 1963/65 as shown in their time versus growth rate (Figure 1) and even from the most critical exponential rise in 1) the both polar ice sublimation and 2) all Oceanic heat contents; the two huge safety valves in huge Global temperature rise control.

Although, most of the contributions to this issue have increased much with the passage of time as summed up for $\mathrm{CO}_{2}$ in [6], none individually, nor all

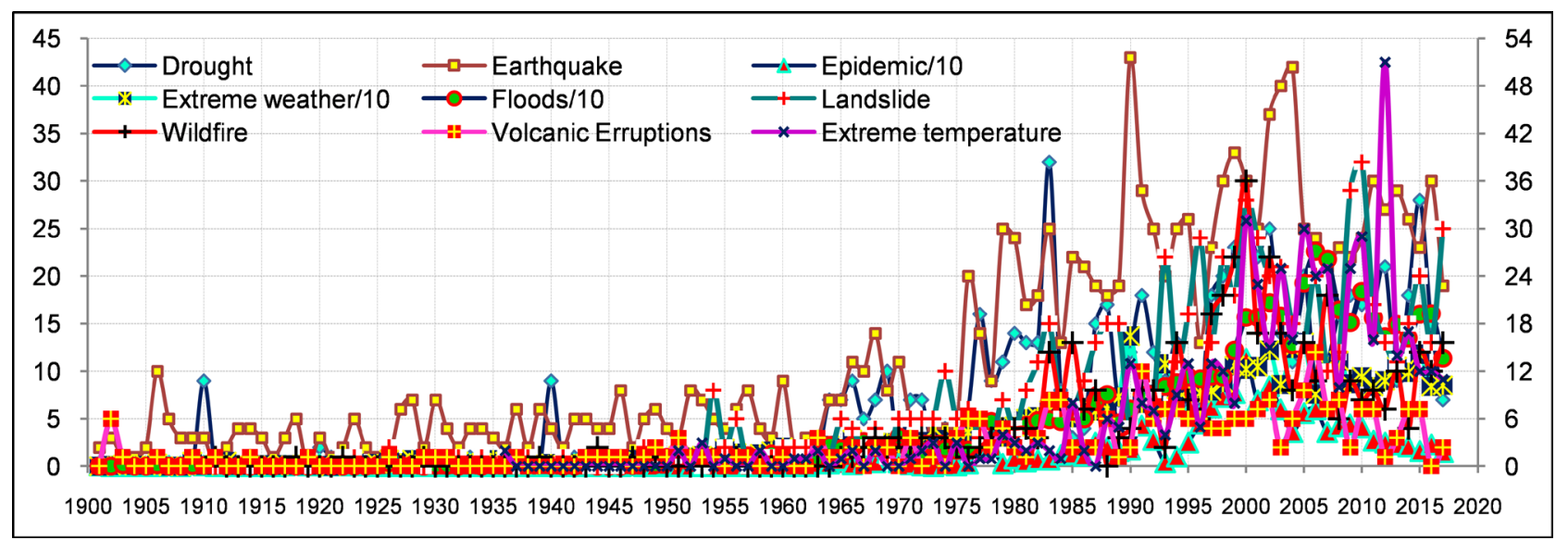

Figure 1. Global hazards growths [5] with time, showing extraordinary growth after 1965. The only major reason of this is IBWT implementation in 1960. The three underlined hazards with extraordinary figures are reduced through dividing by 10 . The $y$-axis scale of extreme temperature is shown on the right. 
collectively match with this historic turn, in time, quantity and persistency of this change. The main, rather the largest reason behind this extremely huge and mother of almost all disastrous phenomenons was not located until early 2019. In [7] water evaporation and precipitation cycle (WEPC) with its Persian Air Wheel Heat Pump (PAWHP) format was emphasized as most effective Global temperature reliever with Global heat export too and with a window for human role in its boosting too as compared to that by polar' and glaciers' ice sublimation and by Oceans heat absorption as huge heat capacitors; both with no change in Global Heat contents and no opportunity for any human positive role. Also contributions of major Global events in GHT were reviewed, but all their time bound fluctuations could not stand for the persistent huge rising rate of GHT. In [8] the major culprit behind this huge rising rate was caught red-handed with number of proofs and evidences, monotonically matching in all time, persistency and stature to a reasonable extent. This was the Indus Basin Water Treaty of 1960 (IBWT), which initiated its implementation in 1960 and step by step completed full water diversion by 1970 and since then Pakistan has been deprived of all the water of her 3 Eastern rivers and through its aftermath, the Earth Globe is being continuously gifted with continuously increasing attacks of sever climatic calamities. Here, it was estimated on bases of some assumptions that IBWT is the major $(55 \%-80 \%)$ contributor in this Global game with obstruction of 9.378 ZJ heat out flow through this continuous Freon (IBWT water diversion) supply stoppage to Global Air Conditioner. Here, it was also elaborated why the 39 MAF water diverted from Pakistan could never ever do the same, rather even the minutest job in India. In [9] potential of contribution of the remaining resources of Pakistan to block GHT growth and drain it's already heaped heat buildup in the last 50 years were estimated. It was estimated that it will take minimum 98 (revised in this below as 42) years to regain its status of 1960 if all these resources are optimally mobilized along with IBWT reversal. Reference [10] found close and strong link between Air wheels generated at Rajasthan, Chulistan and Thar (RCT) deserts to the North Atlantic Tropical Hurricanes (NAH) with the help of their 100 years frequency graph [11] by the guidance of [12]. It, thus envisaged a new paradigm that NAH take birth in RCT deserts of Indian Subcontinent in place of western Coast of Africa (Figure 2) shown in [13]. Reference [14] added further, the link between Indian Monsoons and NAH. A look at 100 years frequency graph of NAH shattered the assumption of 3 month duration of Air wheels generation activity zone at RCT and hence its GHC export potential. From the 3.5 month peak duration of this activity, it became inevitable to revisit its all initial assumptions and estimates of its potentials on more logical and realistic grounds. These estimates as detailed bellow in section $7-10$, shattered the previous paradigm and asserted IBWT as the only or at least mainly, if not the lonely contributor of GHT growth above its general pre 1960 trend.

A new paradigm was presented that at present, the contribution of burning of all the fossil fuels, firing of explosives, wildfires and Green House Gasses (GHG) 


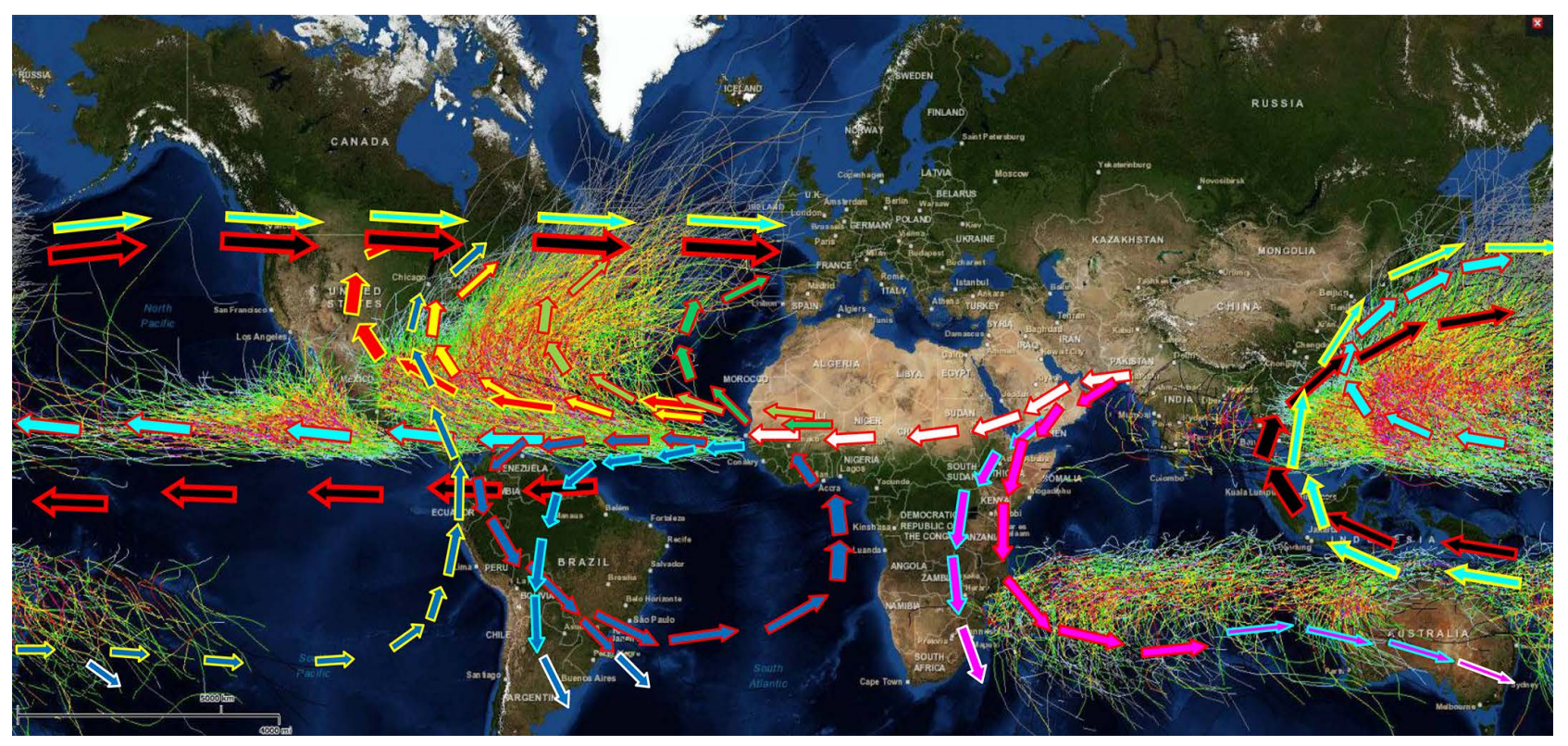

Figure 2. Tracks of Various hurricanes groups, Atlantic, Pacific and Indian Oceans are shown above. The North Atlantic group showing its initiation at African western coast is an old paradigm. The white arrows showing their hidden track with their source in India and Pakistan, is a new paradigm. Red, Yellow and green arrows show their various onward routes. The Indus Basin Water Treaty of 1960 (IBWT) has not only role in boosting of GHT and all the North Atlantic Hurricanes (NAH) family, but it also has role in their transcontinental cross over to Pacific and North Western Pacific hurricanes tribes as their continuation is shown above (red boundaries cyan arrows) and boosting the USA bound/attacking Pineapple Express/Atmospheric River and Europe bound wind and snow storms both from Africa (green arrows) and Canada (yellow boundary cyan arrows) along with its prominent roles in polar (white boundary arrows) and glaciers ice sublimation. The yellow track of NAH may shift to the tracks shown red, hitting central and northern states of USA as a result of Indian Monsoons [14] boosted by extreme Global heat and temperature and directed by African western coastal winds (blue arrows), all fueled by IBWT of 1960. Transcontinental track of Brazilian wildfire aftermath's action is shown by red boundary black arrows and that of Australian wildfire by yellow boundary blue/cyan arrows. 
track shown blue to the Southern Atlantic Ocean after their reversion and channelizing by mountains ranges of South American Continent. The absolute and strong linkage of almost all noted stimulations of NAH was supported by fifteen positive indicators [10], all falling within the highly turbulent era of constantly bleeding of above stated Freon after 1960/70. The large distant association of $\mathrm{NAH}$ with Indian Subcontinent through Indian Monsoons was pointed out in [14] with much exclamation, whereas in [15] such linkage throughout the entire Earth Globe has been presented for 2017/2018 Californian wildfire and its aftermaths. A similar unfortunate catastrophic aftermath of large distant activity is the recent thrash of 2019's Brazilian wildfire with transcontinental routes shown (Figure 2) by red boundary black arrows. It has also dragged the 2019/2020 Australian wildfire into unprecedented actions to have a lime share in huge worldwide disaster in form of multiple strokes of further wildfires, heat waves, heavy wind and snow storms, heavy rains and huge floods etc, in \apan. Australia, New Zealand, South Korea, Indonesia, Bangladesh, India, Pakistan, Middle East, USA, Canada, Europe as reported in electronic media and many others not highlighted and those yet in the pipeline. The main tracks of Australian wildfire are shown by yellow boundary blue arrows showing extreme snow storms attacks on USA \& Canada from the Mexican bay side and to the Canada, northwestern USA States and Europe from North Pacific side shown by yellow boundary cyan arrows. The potential isolated and combined user of this North Pacific track along with Australia are South America (Brazil) and USA through wildfires, Africa through wind blasts boosted by sun heat radiations and Indian subcontinent through its thirsty air wheels, both directly and through triggering the extreme agitation to all the other three in this list through its extremely elevated GHT baseline scenario as the aftermath of its IBWT implementation. Thus IBWWT has not only direct role in all the North Atlantic Pacific and North Western Pacific hurricanes tribes through its transcontinental crossover of RCT generated air wheels to Pacific as shown hy red boundaries cyan arrouss (Figure 2) but also in boosting the USA bound Pineapple Express or Atmospheric River and Europe bound wind and snow storms both from Africa (green arrows) and Canada (vellow boundary cyan arrowsh) indirectly through its pushofthe USA Brazilian and Australian wildfires and East African Wind Blast through its constantly elevating Global Temperature The rellown track of NAH mav shift to the red tracks, hitting central and northern USA states as a result of Indian Monsoons. [14] boosted by extreme GHT and directed by African western coastal winds all mainly fielded and by $I B W W T_{\text {in }}$

As the major Global Scientific Community and the Global Ruling Class has not come across the findings and the recommendations of [7] [8] [9] [10], hence no proper activity to overcome the challenges has been launched as yet. The disparity of this research with almost all others about this extreme Global Heating is that those were mostly focusing on the heat input to the Earth Globe or its retention in atmosphere by Green House Gasses (GHG) to find out the reasons 
behind this, which in total is at the most contributor of $10 \%-15 \%$ of its present rate of rise, whereas this research has Divinely hit on huge blockage of its transmission to the troposphere, which is the main contributor to GHT growth, almost more than $81 \%$ as re-estimated in subsection 7.1 .3 below. Hence, all the efforts thus otherwise suggested could not reduce the speed of GHT horrible rise. In [8] [9], this blockage of Global heat transmission to the troposphere through the Devine fitted Global Air Conditioner (GAC) by an unscientific political measure is presented with solid proofs. It is highlighted there that Freon of this GAC, the irrigating 33 - 44 MAF water of eastern three rivers of Pakistan has been diverted to India from its scientifically most vital natural route under most dangerous and globally most horrible move of twentieth century, the Indus Basin Water Treaty in 1960 (IBWT) by World Bank, USA, UK, Australia etc. This diversion initiated in 1960 and completed by about 1970, is fully functional since then. This has continuously pumped in the GHC balloon and put its family on such an extremely steep rising track that result of the entire natural or human remedial measures have become absolutely insignificant. $A$ very important thing to note is that the frequency, intensity, tracking/steering and brutality of North Atlantic Hurricanes' family along with GHT and its family growth can be only blocked and mainly governed directly and amicably through Pakistan to force it to a favorable/beneficial status through (a) reversion of the said water back to Pakistan and mobilizing optimum irrigation in $\mathrm{Pa}$ kistan comprising on the other two sub-parts ( $b$ \& c) of GAC detailed below. The link between NAH and Indian monsoon pointed out in [14] needs clarifications, given in following paragraphs along with revisiting of the assumptions made in [7] [8] [9] for their realistic, logical and vital updates and their dependent results.

\section{GHT, NAH and Indian Monsoons}

It is confirmed that Indian Monsoons have very strong linkage with NAH as is evident in Figure 3 by almost complete matching of trend of the Major NAH (green line) [16] and Indian Monsoons strong indicator, the Indus River flows of July (blue line) from 1998 to 2016 recorded by [17] at location 294. The trends of 17 out of total 19 years exactly match, while 2 mismatching years are pointed out by red arrows. In the mismatching year 2004, the monsoons were a bit late and August flow of river Indus has rising trend matching with the trend of NAH. Thus 18 out of 19 match the trend. While in year 2013:

1) Either Indus river flow may be only due to melting of glaciers, hence no appreciable monsoon push to the air wheel and no major hurricane.

2) Or it might have fizzled out on the way to become a normal storm, but the normal storm too has decreasing trend (Figure 3).

3) Or there may be no air wheel generation.

a) as it may be throughout cloudy in RCT, hence no air wheel generation.

b) or there may be sufficient rainfall in Rajasthan. 
c) or there may be both cloudy and rainfall in Rajasthan.

Thus either there is no monsoons' push or no air wheel generation to match in timings with the river flow. Each of these two 2004 \& 2013 years (Figure 3) are within two groups of four years $(2002,2003,2004,2005$ ascending from 2 to 7 and 2010,2011, 2012, 2013 descending from 5 - 0, i.e. equal and opposite shift in both cases) each additionally and inversely modulated over and above on their further track by approaching and departing role of Venus in its 2004 \& 2012 transits to be discussed in forthcoming article on "Solar, Lunar and Venus roles in some Global climate events". Even without 2013, the Indian Monsoons are the main, almost $\mathbf{9 5 \%}$ driver/directors and booster of Major $\mathrm{NAH}$, in frequency, intensities, targets and the routes. These Monsoons have two folds role in steering and boosting NAH and GHT. One is that of Monsoons air blast or its kinetic energy and the second is that of its rainfall. These are discussed here below.
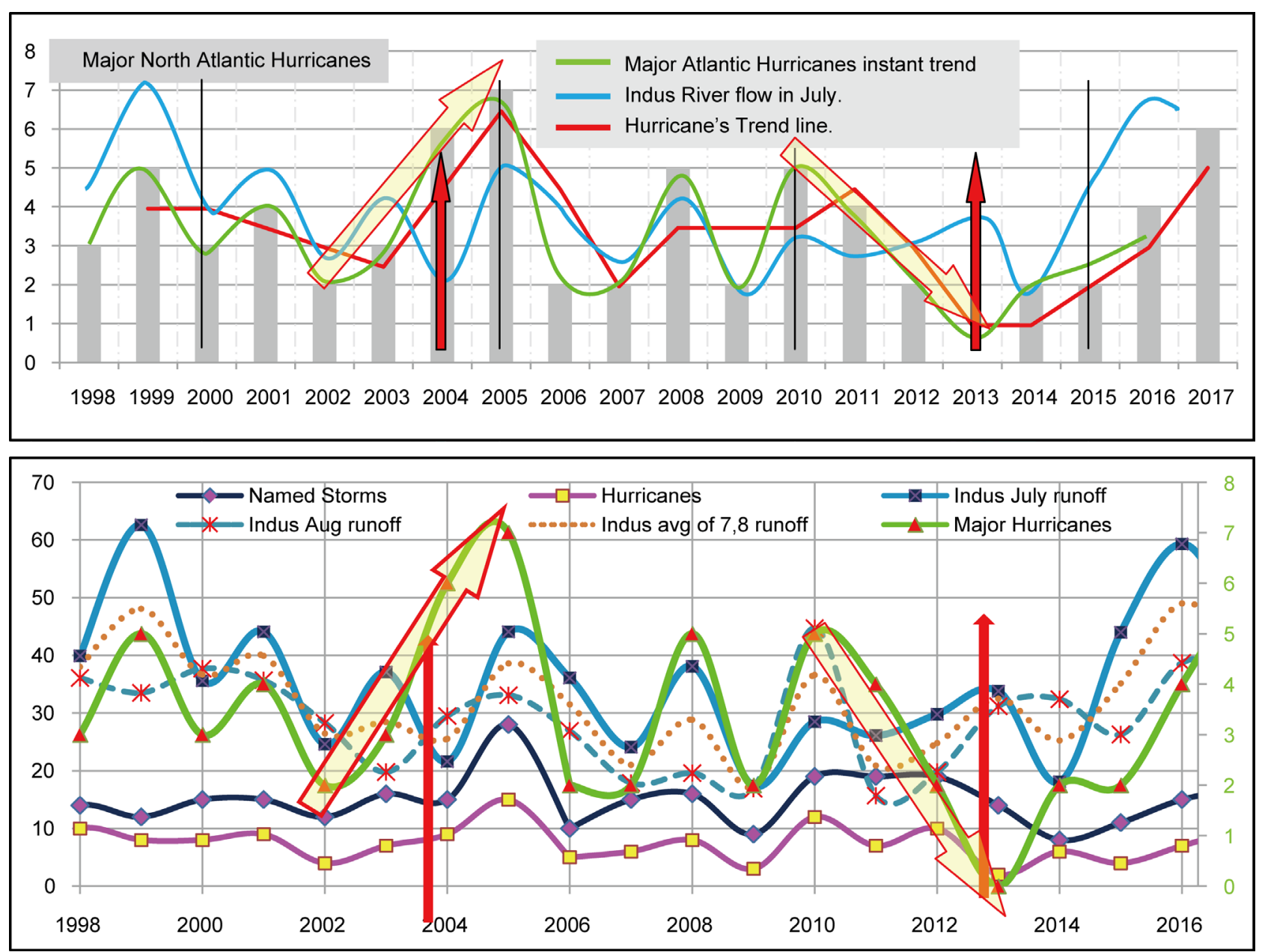

Figure 3. The top is the bar chart of Major North Atlantic Hurricanes [16] with instant (green) and moving average (red) trend lines and Indus river July (blue line) flows [17]; while at the bottom are July/August flows of Indus River, NAH and named storms with scale of Major NAH highlighted on the right for its analysis. Instant trend of major NAH (green) line of 17 years out of total 19 years (1998-2016), exactly follows the trend of Indus River flow of July, the Indian Monsoon representative. The 2 mismatching years are pointed out by red vertical arrows. 


\subsection{Indian Monsoon's Air Blast Role}

Prior to rolling air wheel generations at RCT deserts, the route of Monsoons is shown Green in Figure 4 and Figure 5. At the end of June, sea to land breeze (SLB) ceases and these results in air wheel generation by Sun heat radiations on RCT deserts [7] [8] [9] [10] prior to strong growth of land to sea breeze (LSB). These air wheels roll westwards in one, two or three trains due to Earth Globe eastward rotation about its polar axis [7] [12]. During this time the Indian eastern (speed booster) and western (direction director) coastal SLB, both channelized by South Indian topography, which were pushing and guiding the pre-monsoons to the precipitations trap of northern area of Pakistan as shown green in Figure 4 and Figure 5, cease and let its sizable part go straight to RCT deserts and push the air wheel generated there to slip and roll westward faster. These air wheels carry on rolling and slipping vertically till Atlantic, where most of these are toppled to roll horizontally by African western coastal wind (track) shown blue and pink respectively in Figure $2 \&$ Figure 4, with their very rare chances to escape un-toppled while transforming into NAH. These air wheels or hurricanes become visible at about middle of Atlantic Ocean when sufficient water vapors absorbed by these air wheels from the Oceans condense and form clouds. The intensity of hurricanes and storms (Figure 6) are directed by GHT through temperature of Atlantic Ocean [18]. The role of Oceans in establishing the category of Hurricane depends on its surface temperature and time of its contact with the air wheels [19]. If its temperature is low, water evaporation will be slow and less and Ocean supplement to the air wheels through absorbed water vapors will be less, hence net kinetic energy of the hurricane will be less and its category and intensity will be low and vice versa. Thus, at present over Atlantic, reference [18] shows that almost Category 5 hurricanes can never happen with ocean temperature below $82^{\circ} \mathrm{F}$ and Category 4 below $81^{\circ} \mathrm{F}$ (Figure 6), while over the Pacific; it may be $81^{\circ}$ and $80^{\circ} \mathrm{F}$ respectively [19] due to long distance and hence large contact time for heat and mass transfer. Thus, higher is the GHT, the more

1) in numbers is the air wheels generation,

2) energetic are the air wheels,

3) energetic are the Monsoons and more sever is their push to the air wheels,

4) is the African heat input to these air wheels,

5) energetic is the toppling of air wheels and

6) sever is the building up of intensity and category of hurricanes by Atlantic Ocean,

Hence more deep penetrations in USA are of the resulting NAH. Thus IBWT has one direct NAH brutality boosting roles through Global heat energy outflow obstruction forcing heat intensity to Indian air wheels (IAW) and at least five more through its elevation of GHT, all nourished, nurtured and grown up by the grace of IBWT. The USA landfall of Multiple Hurricanes at a time and those of diameters $20 / 30 \mathrm{Km}$. or more are the supplements of post IBWT implementation era through elevated GHT (NPD). 


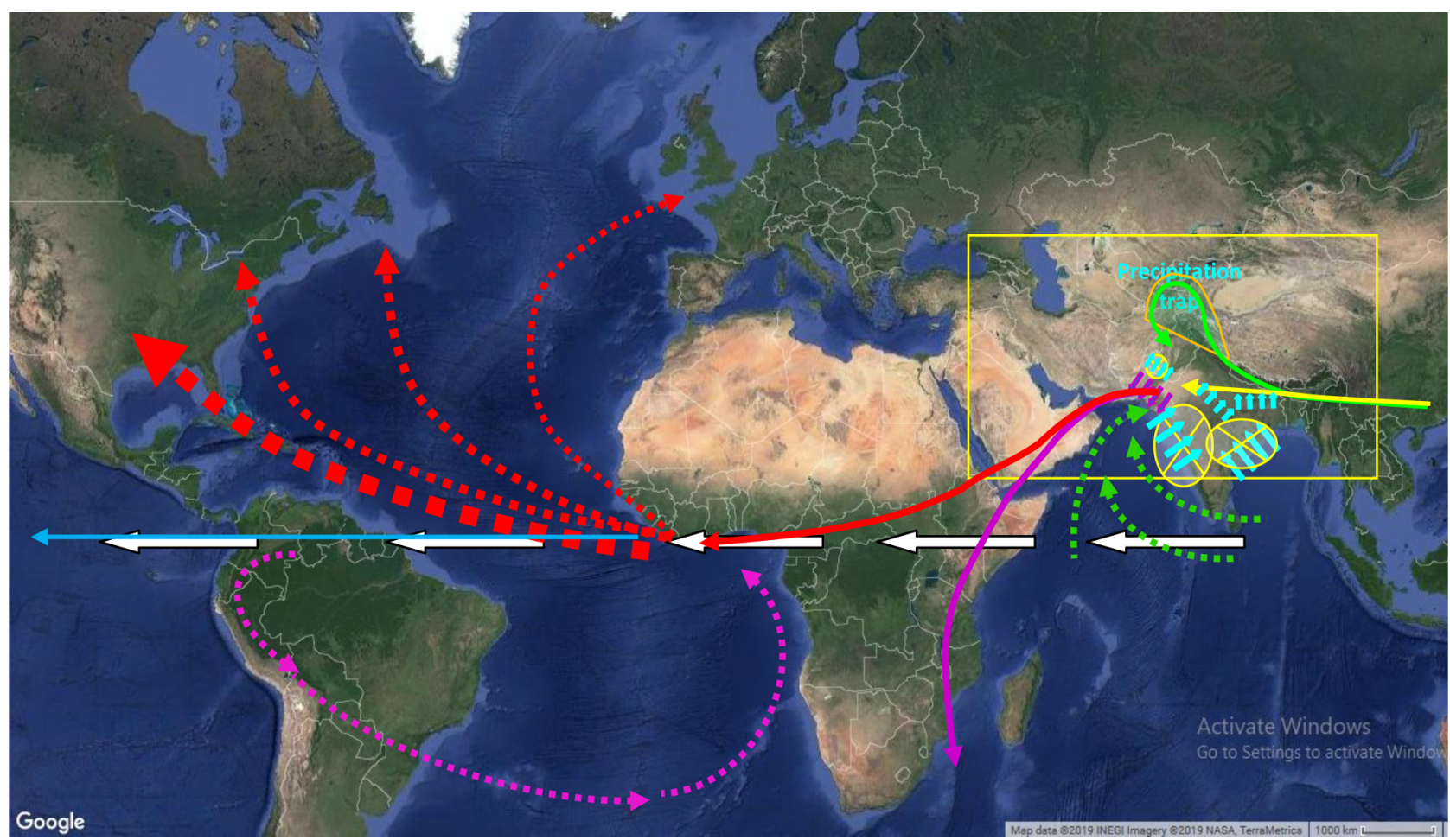

Figure 4. Transcontinental routes of Indian Originated Air Wheels route (continuous red line), its pusher or booster, the Monsoons (continuous yellow line) de-tracked from their green route as a result of their ceased pusher and direction director (yellow crossed continuous cyan arrows), the Indian eastern and western coastal winds respectively by the end of June. White arrows show easterly and red dotted lines show resulting $\mathrm{NAH}$, while continuous blue line is the track/ route of transcontinental crossover of part of the RCT Indian air wheels.

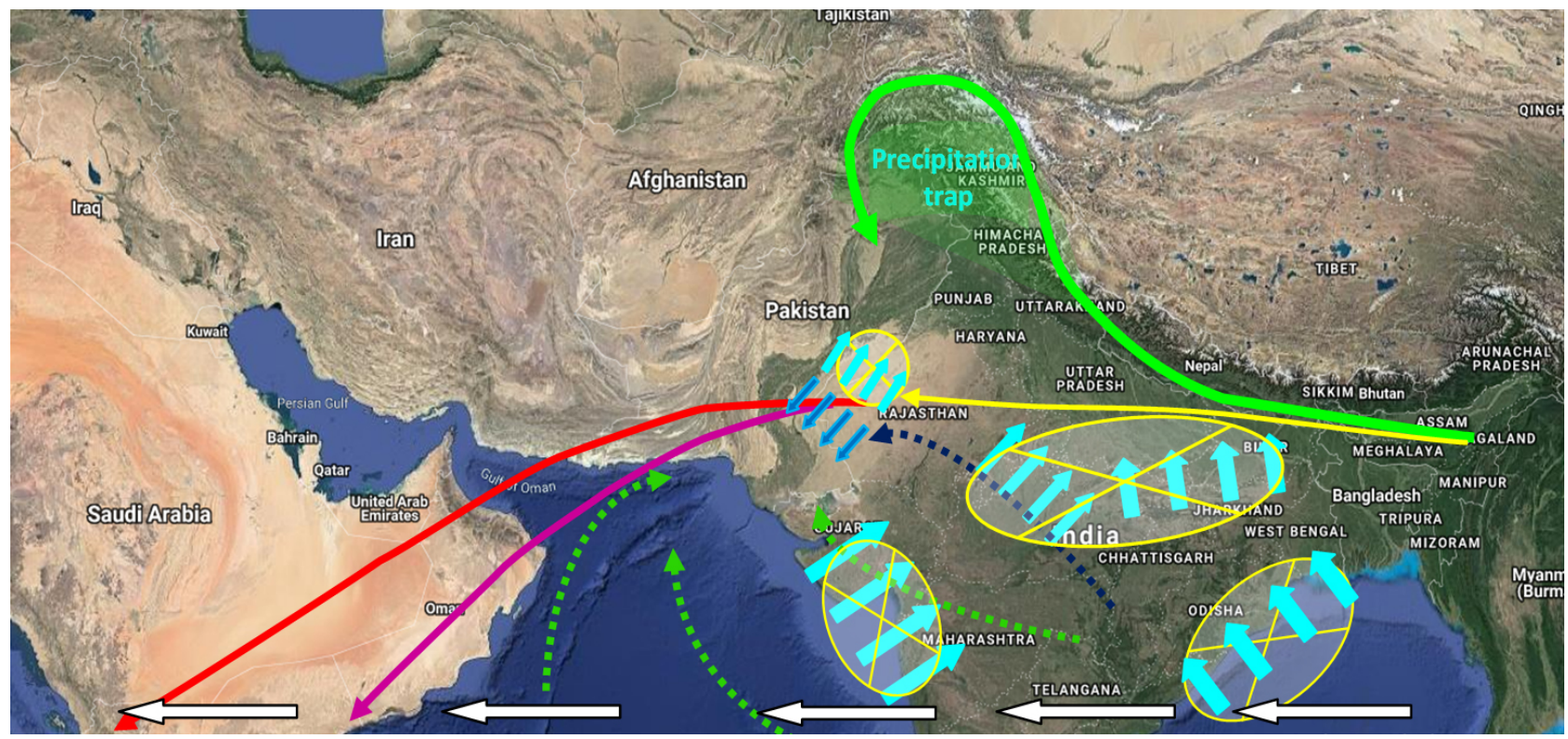

Figure 5. Yellow line, the free-track Monsoons are pusher of RCT deserts generated air wheels, while green dotted lines representing Indian Ocean wind blasts, slow down their speed except the one represented by dark blue dotted line. These blasts (green dotted lines) may result in fizzling out of hurricanes at about Saudi Arabia, while those with boosted speed by Monsoons may result into deep penetration in USA with extreme damages and huge losses. 


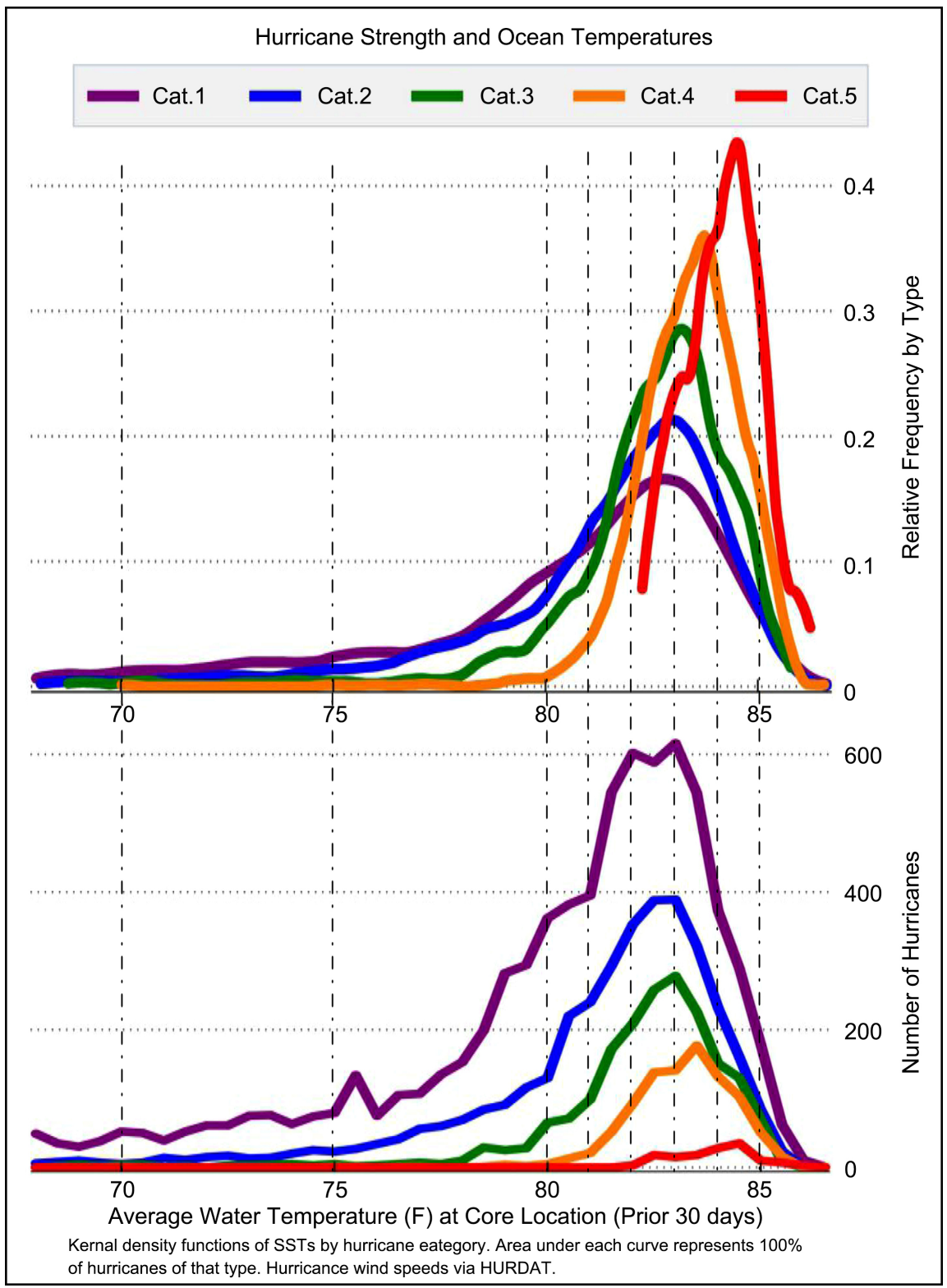

Figure 6. Above shows a look at hurricanes and ocean temperatures correlation over Atlantic Ocean. It shows that almost Category 5 hurricanes can never happen with ocean temps below $82^{\circ} \mathrm{F}$ and Category 4 below $81^{\circ} \mathrm{F}$ and over the Pacific it is $81^{\circ}$ and $80^{\circ} \mathrm{F}$ [18] [19] respectively due to more in-contact time on a long distance.

Thus, it can easily be concluded that within a short duration, the GHT is going to build up a terrible scenario beyond all imaginations; crossing all boundaries and limits, overruling all rules and regulations, perishing all barriers, hurdles and bindings, resulting into extreme calamities and catastrophes over the entire Globe like its recent mini, rather tiny European 2020-version, unless its immediate optimum blocking measure are taken as recommended at the end.

As above, some air wheels escaping from African coastal wind blast and even cross over to Pacific Ocean and a few are also reverted and redirected to South- 
ern Atlantic by Southern American topography as shown blue and pink in Figure 2 \& Figure 4 respectively. Some of those crossing over to Pacific may promote tornados and typhoons in Japan and Fareast Countries. This is because lime Share of Indians air wheels are forced towards USA and a few remaining lone alone, rarely un-toppled on the way may only generate Typhoon or Tornado if these do not fizzle out on the way. This differentiates the types and nature of Philippine's/Japan's and USA landfalls. As shown in Figure 2 and discussed below, some of the offshoots of IAW going as directed by eastern coastal area of Africa and two channels of South America crossover the Southern Sea directly and some African part via Australia launch 3 prongs attack on ice heap of Antarctica. As discussed below, the prime mover behind all this is the extreme Global heating mainly and routinely by Sun, but is being nourished and nurtured almost solely by IBWT through blocking of its out flow from its most wanted natural route and this has wide opened the gates of all the worldwide huge disasters and extreme calamities [5]. The green dotted lines (Figure 4 and Figure 5) representing Indian Ocean wind blasts routes which slow down the speed of said air wheels, being in somewhat opposite direction except the one represented by blue dotted line. These winds (with route shown green) result in fizzling out of hurricanes before reaching Atlantic, while those with boosted speed by solar generated Indian Monsoons may result into deep penetration in USA with extreme damages and huge losses. An interesting and notable feature is that these vertically rolling air wheels directed by Baluchistan mountains move to western coast of Africa through Saudi Arabia, Somalia and Sudan etc. mostly unobserved and carried over by the easterlies. Here, these are toppled into horizontal counterclockwise rotating wind storms or hurricanes by the African western coastal wind blasts, the offshoot of easterlies reverted and directed by topography of South American continent as shown in Figure 2 \& Figure 4. The resultant momentum of RCT air wheels and African coastal wind blast decide the direction, speed, severity, brutality and target of these hurricanes with respect to eastward rotating earth at varying linear speed as per its latitude position. Thus, near the equator these move westward relative to the eastward higher speed of earth, while when they reach the latitude higher than $35^{\circ}$, the linear speed of earth become less than that of storms and thus their absolute eastward speed dominates and these hurricanes or storms start moving eastward. The storms hitting Canada, UK and Europe fall in this category. The IAW may go in one (from Chulistan), two ( $2^{\text {nd }}$ from Rajasthan) or three ( $3^{\text {rd }}$ from Thar) trains in parallel up to Atlantic Ocean forced by sun radiation's heat at higher baseline status of GHT and during their toppling, two, three or four air wheels may merge into one horizontal rotating hurricane with one, two, three or more spawned tornados, if these are close to each other at the time of their toppling. If these are far apart, these may go side by side in parallel or one after the other or may go on their own route. The numbers of air wheel trains, number of merging air wheels, spawned tornados and multiple tornados at a time are all dictated by 
GHT status and these all have grown up extraordinarily in era of GHT growth since the IBWT implementation [10], confirming these as aftermath of IBWT. The diameters of Hurricanes are almost vectorial sum of diameters of merging air wheels along with contribution of their premerger mutual location. Thus multiple hurricanes at a time and of diameters more than $10 \mathrm{Km}$ are all the aftermath of elevated GHT nourished and nurtured only by IBWT. These processes are all scientific and natural, have no opportunity for any human role except IBWT reversion. The IAW are the main component of GAC detailed below and with the help of water vapors supplied by water evaporation from irrigated area of Southern Pakistan; these can transport Global heat en-route to upper cold atmosphere like the Persian wheel water pump, depending upon quantity of available water and its surface area in Southern Pakistan. Without water vapors their performance is only $11.76 \%$, while with optimum or maximum water vapors it is $100 \%$ [7] [10]. Managing the wastage control of water availability for irrigation through its storage in dam, optimum development of irrigation and drainage systems and preparation of additional fields for irrigation only in Pakistan (elaborated below) is the only window for its safe human control of GHT as well as its fueled calamities.

\subsection{Indian Monsoons Rainfall Role}

The resulting rainfalls has a bit opposing effect by reducing the temperature and energy of air wheels except the rain and dense clouds on Rajasthan which will obstruct the air wheel generation as long as clouds are there and for a few days further in case of rain. This is an unwanted event in view of extreme Global Heat dissipation demands and perhaps wanted for NAH control. However, rainfall in Southern Baluchistan, Chulistan, Thar and Sindh and optimum irrigation supply in these areas is most fruitful both for GHT control and NAH family moderation [7] [8] [9]. The water vapors added to the air wheels will carry on pumping the heat of earth surface and its atmosphere to the upper cold atmosphere of troposphere almost up to the western end of Atlantic Ocean. The water vapors only from the above stated area act as Freon in the Divinely fabricated/operated natural GAC as its remaining route is all dry till Atlantic Ocean while its contact with Persian Gulf and Red Sea is for a short while, thus negligible.

\subsection{Unique Role of RCT Deserts in Global Climate Control}

Almost, throughout the whole world, only RCT deserts has the role of air wheel generation and irrigation of Pakistani Chulistan, Thar, Thal, Sindh and Baluchistan if these are well irrigated have the only opportunity to supply adequate amount of water vapors to control GHT and moderate the ruthlessness of NAH family and this opportunity is in the hand of human beings through management of the available natural water and irrigate-able land resources in Pakistan. This water demand was divinely met with by the irrigation through natural flow of eastern three rivers, Ravi, Beas and Sutlej, but unfortunately, it was completely 
diverted to India in 1970 as a result of tragic IBWT, and through this move, whole the world is secretly hurled into extremely large and numerous troubles resulting into extremely huge disasters, almost all over the Earth Globe, continuously since then. This tragic move is $3^{\text {rd }}$ of its kind in the same area [8] [20] [21], with same targets and same results. Earliest 2 are not much felt, being in the pre-industrialization era and due to not much attention on cause and effects on a wider Global scale. Some 4000 year ago reversion of river Sarasvati [20] along with other global implications, might have targeted the Old Civilization in Oman, Yemen, Rub-ul-Khali and Madain-e-Saleh of Saudi Arabia and perhaps departure of last ice age, while the barraging of Ghaghar-Hakra-Nara [21], a few hundred years ago might have blocked raining in Iran, Yemen, Saudi Arabia, Somalia, Ethiopia, Sudan and Sahara till western coast of Africa.

The Indian irrigated area does not have any desert on its east in topical region to generate air wheels for Global climate control to benefit from its irrigation supplies. Thus the above stated diverted flow is pushed to a black hole with respect to Global heat dissipation process and hence demolished the barriers to the brutality of Global Calamities. The reversion of all the said water back to Pakistan along with dams storage of all the available non-perennial water for maximum water evaporation feed to extremely safe and saving cyclic process through irrigational supply during whole the year, as well as its multi-year management, the optimal development of irrigation system and all the area worth irrigation is a very vital, urgent and prime need of whole the world and most important opportunity for the mankind to regain its pre-1960 safe environmental status. Any extraordinary rains or floods in the above stated area, although their very small portion is gripped by the evaporation, yet these promptly indicate their performance in physical and geographic status of the Global Heat Contents, Global Temperature [7] [10] and all other indicators. Thus, the Indian Subcontinent has following three most prominent, basic and unique contributions in engineering the Global climate, GHT, NAH and GAC.

1) Air wheels generated at RCT desert, the driving current of GAC.

2) Indian Monsoon, the booster and pusher of air wheels or GAC pump.

3) Pakistan irrigation system, the supplier of Freon to GAC with 3 steps regulator detailed bellow.

Only the last one has an opportunity for the mankind to control or boost its performance by providing adequate water vapors to RCT air wheels through flow regulation with storage dams and irrigation system and widening its surface area through land irrigation and agro-plant growth to accelerate water evaporation. This has been closed by IBWT since 1970.

\section{Global Air Conditioner}

The Creator of the entire Universe has created each and every thing most suitably beyond our imagination and so has been done for the Earth Globe and all its components. For continuous resetting of its environments safe and suitable, He 
has created a huge Global Air Conditioner functioning during all the hot season in most populated Northern Hemispheres, particularly during summer/autumn. It has its main components as.

1) Sun radiations and RCT desserts as generators of multiple air wheels trains,

2) Chulistan, Thar, Thal, Southern Punjab, Sindh and Baluchistan as irrigation water surface extenders for its evaporation,

3) Pakistani rivers, particularly the eastern three rivers as suppliers of water, the Freon of this GAC,

4) Indian Monsoons blast particularly directed in phase both in timings and direction with the air wheels generation as booster of their rolling speed and performance,

5) Easterlies as air wheels carrier and their slipping speed booster,

6) Long track from Pakistan to the western coast of Atlantic Ocean,

7) Northern Africa as huge heat distributor to the whole World in the absence of water vapors saturated RCT air wheels trains,

8 ) and the Troposphere an extremely huge sink for heat.

The first one is as the driving voltage; $2^{\text {nd }}$ one as air wheels generator, $3^{\text {rd }}$ one as Freon supplier, $4^{\text {th }}$ and $5^{\text {th }}$ as driving current, $6^{\text {th }}$ as the evaporation and precipitation compartment and $7^{\text {th }}$ major heat distributor to the entire global, $8^{\text {th }}$ as the condenser in this GAC as tabulated with other main components and their roles in Table 1 . The mankind has the only opportunity to provide maximum water, the Freon and maximum irrigate-able area for water surface extension, the above $2^{\text {nd }}$ and $3^{\text {rd }}$ components to switch on, regulate and boost the performance of this GAC.

Table 1. Global Air Conditioner's Components and their roles.

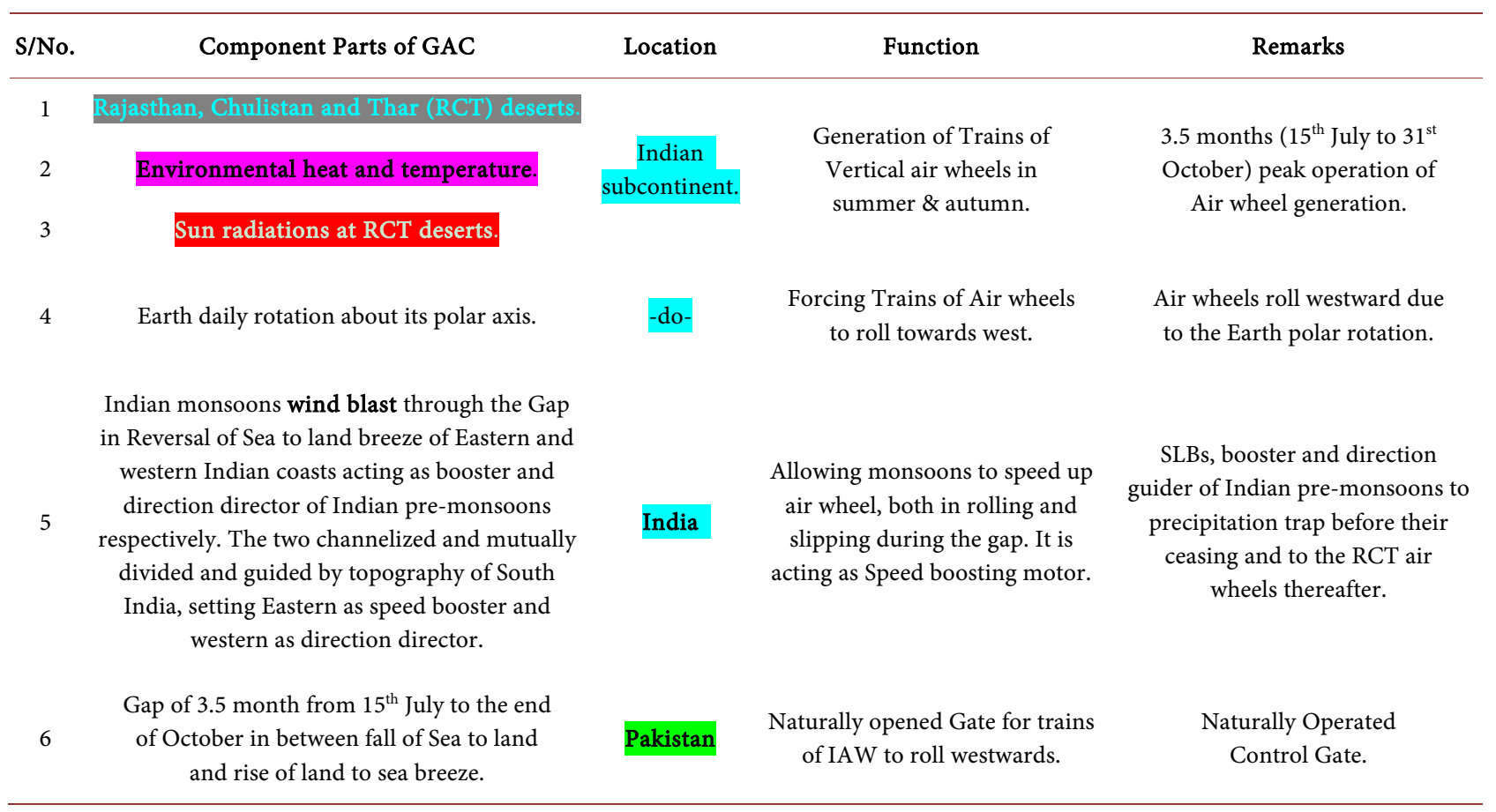




\section{Continued}

Indian monsoons

rain fall in Pakistan

Irrigation of south-eastern Pakistan, the GAC air wheels trains track. Blocked

9-a completely since $1971 / 72$ by blocking flow of 3 rivers; Ravi, Bias \& Sutlej under IBWT Implementation in 1960.

( $1^{\text {st }}$ part of GAC, mainly Global).

Optimum Irrigation of Northern Pakistan, the track of air wheels in local evaporation and precipitation cycle, partly and basically fed by the monsoons and mainly by its re-recycling of WEPC amounting to be 393 MAF water circulations. $\left(2^{\text {nd }}\right.$ part of GAC, all Local, based upon storage $\&$ irrigation system developments).

Irrigation of Chulistan, Thar \& Baluchistan of Pakistan; the track of air wheels of GAC.

9-c (This part can be active only after 9-b water storage and irrigation system development.) (3d part of GAC, mainly Global). Easterlies. Northern Africa.

All the three Oceans, recipient and storage of mishandled Global Heat, quantity vise in descending order are, Atlantic, Southern, Indian, and Pacific with Northern dominancy.

13

South American Topography (role in case of IBWT crippled GAC highlited pink)

African coastal wind

14 (role in case of IBWT crippled GAC highlited pink)
India

Pakistan.
Obstruction in GAC performance.

Most vital only in Pakistan.

\section{Pakistan.}

Pakistan.

\section{Pakistan.}

Tropical zone around the Earth Globe.

Northern Africa.

The entire Earth Globe.

South

America

African

coasts.
Air wheels trains transcontinental carrier and GAC accelerator.
Freon of GAC with 14.235 ZJ

Global heat transportability. Its

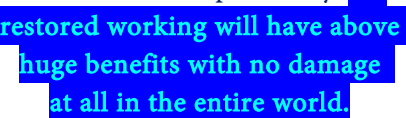

Freon of local part of GAC with local heat export potential of $9.893 \mathrm{ZJ}$. Its working has no damage at all to any one in the entire world, rather most beneficial to India, Iran Afghanistan, \& Middle East by additional moderate rains

Freon of GAC with 15.78 ZJ Global heat transportability.

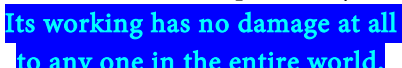

to any one in the entire world.

Main Global heat transmission to troposphere by reinstated GAC in place of its Global dispersal.

Safety Valve and storage for mishandled heat and booster of water evaporation \& hurricanes promoters \& categorizers.

Recycling a part of easterlies \& Indian Air Wheels.

Western, toppling of Air wheel to NAH and steering its direction.
Dependent upon IBWT reversal \& optimum water storage and irrigation system development in Southern Pakistan.

\section{Standalone and unique re-recycling system. In this \\ process, the rivers flow} contribution of Monsoon is about 100 , that of its re-recycling 150 , local rain 120 and rains of vapor escaped abroad 25 - $30 \mathrm{MAF}$

Dependent upon 9-b optimum water storage \& irrigation system and all irrigate-able areas development.

\section{Main power source or the driving current.}

Evaporator and Main heat source.

These normalize and decrease

Global environmental

Temperature and accelerate GAC.

NAH toppling and steering facilitator and a gun to fire heat/kinetic energy at Antarctica

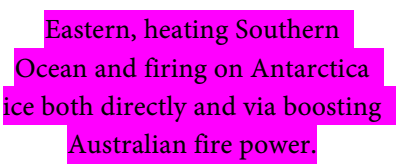

Condenser. 


\section{Indian Subcontinent Roles in GAC}

Out of 15 component of GAC stated in Table 1, 9 are from Indian subcontinent; 4 common in India and Pakistan, 2 solely in India and remaining 3 solely in Pakistan, while all the three steps (9-a, 9-b \& 9-c) of its regulator, the only window for its control by human beings is all in Pakistan. One of the Indian 2 parts $\left(5^{\text {th }}\right)$ is promoter, while other $\left(7^{\text {th }}\right)$ is opposing GAC performance. India however, has further $\mathbf{2}$ additional adverse roles in GAC, needing scientific management to reduce their adverse roles.

1) Indian generated Smug by firing its crop waists during winter introduces a huge hindrance to Local WEPC part of GAC stated above at 9-b over and above huge and acute health problem in Pakistan, an extremely serious challenge for World Health Organization (WHO).

2) Extraordinarily huge heat and pollution input by India from its industries during summer generating heat waves in Pakistan and boosting brutality of NAH and GHT through RCT air wheels intensity. This is another serious issue to be taken care of by WHO.

This GAC only with 9-a part was functioning perfectly well when its Freon (the water) was diverted by unscientific human act of IBWT implementation. This extremely boosted the GHT and NAH to highly alarming status as highlighted in [7] [9] and has shown the stars to the mankind in the daylight at noon. IBWT reversal must anyway be made fully; overruling Indians stance and it is all highly fruitful to the entire world without any trouble to anyone. Its $2^{\text {nd }}$ potential contributor (9-b) as stated in Table 1 is misguided mercilessly (to be elaborated in forthcoming articles) and hence GHT is galloping up and up uninterrupted. The last two steps of GAC regulator (9-b \& 9-c) are yet to be initiated.

In [10] matching association of NAH and RCT deserts generated air wheels was presented with 15 supporting points along with mutual matching collaboration and association support in timings of NAH 100 year frequency graph as stated below.

\section{North Atlantic Hurricanes 100 Years Frequency}

For more insight, the graphical presentation of NAH 100 Years Frequency as given in [11] is advanced by ten days (travel time from Pakistan to USA) in Figure 7 to match it with air wheels generation stage at RCT deserts and is distributed in different sectors as per their variations. Time duration of different sectors is also shown in Figure 7, while in Figure 8, their relative location to the Sun declination with respect to Earth along with seasons of the Northern Hemisphere [22] is elaborated. A few observation and findings are discussed here bellow.

\subsection{Durations of NAH Peak Frequency Sections}

From Figure 7, the peak rise is of 42 and peak fall is of 63 days. Thus total peak duration is 105 days, contrary to 90 days considered in [5 and 9] for evaluations of heat transport by Persian Air Wheel Heat Pump (PAWHP). An interesting thing is why this fall is so prolonged than the rise? For this, see the air wheels 


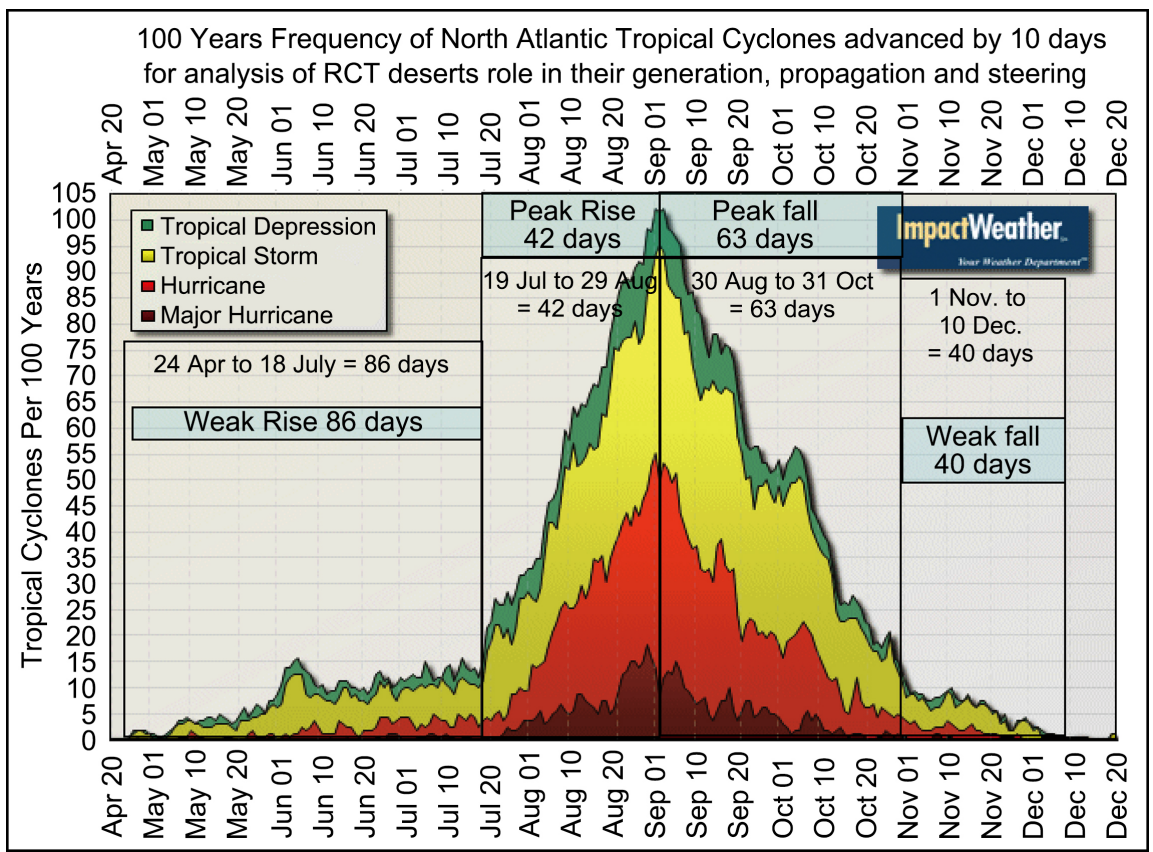

Figure 7. The 100 year frequencies of North Atlantic Major and normal Hurricanes, cyclones, tropical storms and depressions [11] advanced by 10 days for analysis of its correlations with their initiation location parameters. It is divided in a few sectors as per its status.

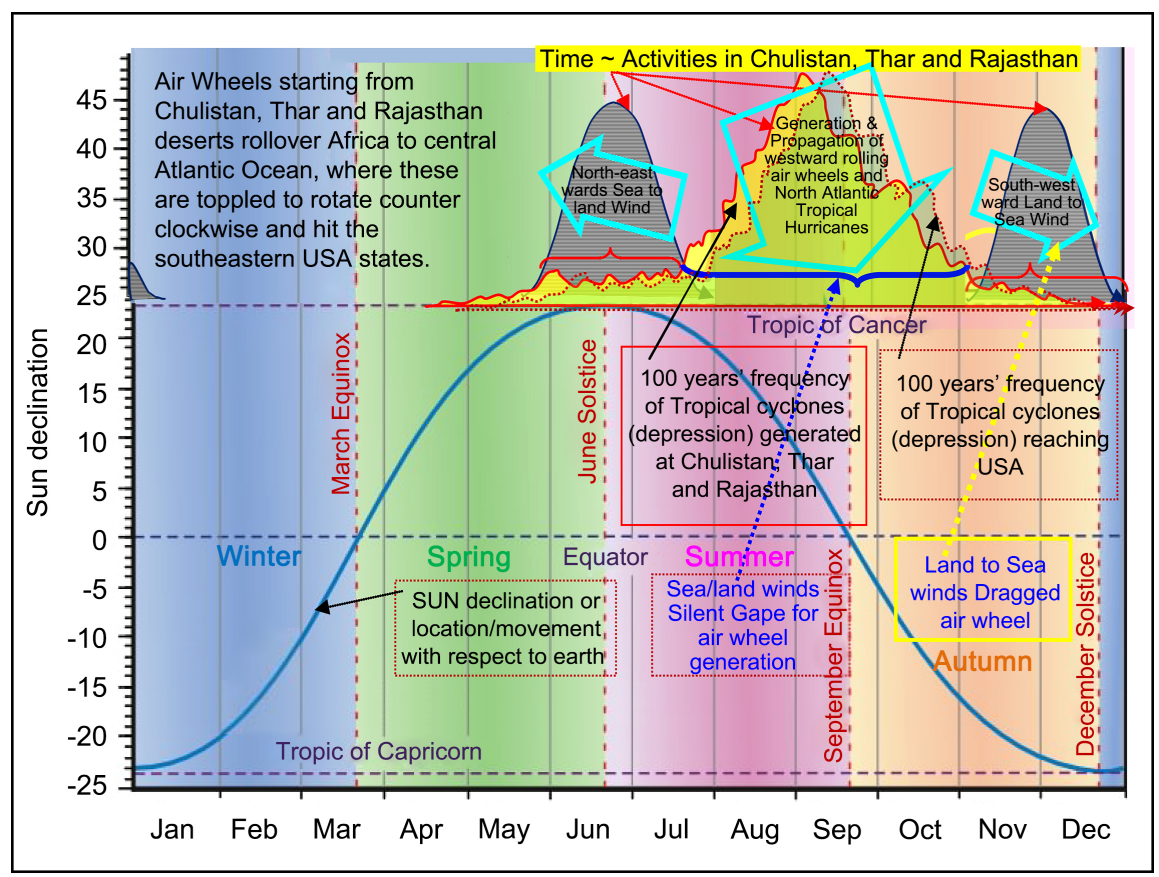

Figure 8. Seasons of a year in Earth Northern Hemisphere are shown with Sun declination [22] and 100 years frequency of NAH [11] timings both at their generations in Chulistan and Thar of Pakistan and Rajasthan of India as westward rolling vertical air wheels and that at their reaching the coasts of USA. The time versus growth and fall of sea to land and land to sea breeze at their generation stage is shown along with summer follower Gap in between these two, providing the opportunity for air wheels generation by high temperature. 
generation location in Figure 4 \& Figure 5 and Figure 8. The preceding SLB and following LSB winds flowing perpendicular to their coastal line direction are equally inclined to air wheels rolling direction, the preceding one is somewhat in opposition and the follower one in equally support at about $45^{\circ}$. The preceding one is opposing the flow, hence peak rise has short duration, while the follower is the pusher in support and hence has long duration.

\subsection{Peak Rise and Fall Coverings' Time Period}

The end covers are 86 and 40 days. These eras (Figure 7) also show some off and on opportunity of air wheels slipping away from the grip of coastal SLB or LSB winds when it is a bit loose by any reason and roll away on their normal track to Atlantic Ocean. The approximate rising and falling slops of Hurricanes frequency curves in these eras closely match with agitating temperature rise and fall (Figure 8) over and above GHT baseline and environmental repercussions. This also indicates the NAH strong link with RCT deserts generated air wheels.

\section{IBWT Role in Boosting Global Oceanic Differential Heating}

As per [1], the revised estimates of total Oceanic Heat Contents increase from 1971 to 2015 is $66 \times 10^{22} \mathrm{~J}=660 \mathrm{ZJ}(15.35 \mathrm{ZJ} / \mathrm{yr}$, while global rate $16.48 \mathrm{ZJ} / \mathrm{yr})$. The mutual relative distribution between different oceans is; $17 \%(2.61 \mathrm{ZJ} / \mathrm{yr})$ stored in the Pacific Ocean, 24\% (3.684 ZJ/yr) in the Indian Ocean (northward of $\left.30^{\circ} \mathrm{S}\right), 31 \%(4.758 \mathrm{ZJ} / \mathrm{yr}$ ) in the Atlantic Ocean and $28 \%$ (4.2977 ZJ/yr) in the southern oceans (south of $30^{\circ} \mathrm{S}$ ). The IBWT has three prong attacks on this Oceanic heating. One and the main are through extremely boosted GHT with its dispersal by Indian Air wheel, Easterlies and Westerly flow pattern over the Globe. The $2^{\text {nd }}$ is directly through Global wind movement patterns partially shown in Figure 2. The maximum air blast with highest heat contents are received by Northern Atlantic Ocean, hence leading in heat contents and a bit less by Indian and Southern Oceans by IAW going over and along African eastern coast. The Southern Oceans receives its $2^{\text {nd }}$ dose along with Southern Atlantic Ocean from the portion of IAW and Easterlies diverted by pattern of mountain ridges of South American Continent (Figure 2) and also by its eastern coast. The Pacific Ocean with lead of its Northern part receives its share from the remaining portion of crossing over the Atlantic and American continents as is evident from wind movement pattern shown in Figure 2. The $3^{\text {rd }}$ prong of attack of IBWT is its heat transport through the oceanic currents developed by the earth rotation from its heated higher temperature equatorial portions of all the oceans. The different heat contents of different Oceans are due to their location and hence variation of its committed firing power at various sectors and en-route transmission lines power losses.

\section{IBWT Role in Antarctic, Greenland and Glaciers Ice Sublimations}

The IBWT nourished GHT is the main cause of recent huge growth in ice sub- 
limation rate as shown of 37 Alpine glaciers and both the poles (Figure 9, Figure 10) [24] [25] and all other glaciers through its direct attacks along with southeastward fired Air Blasts through long range gun barrels of South American and African continents, both equipped with heat contents and kinetic energy dynamites as can be seen from clouded air viral and the ice sublimation gone under these attacks (Figure 11, Figure 12). The indirect sever attack on Antarctica

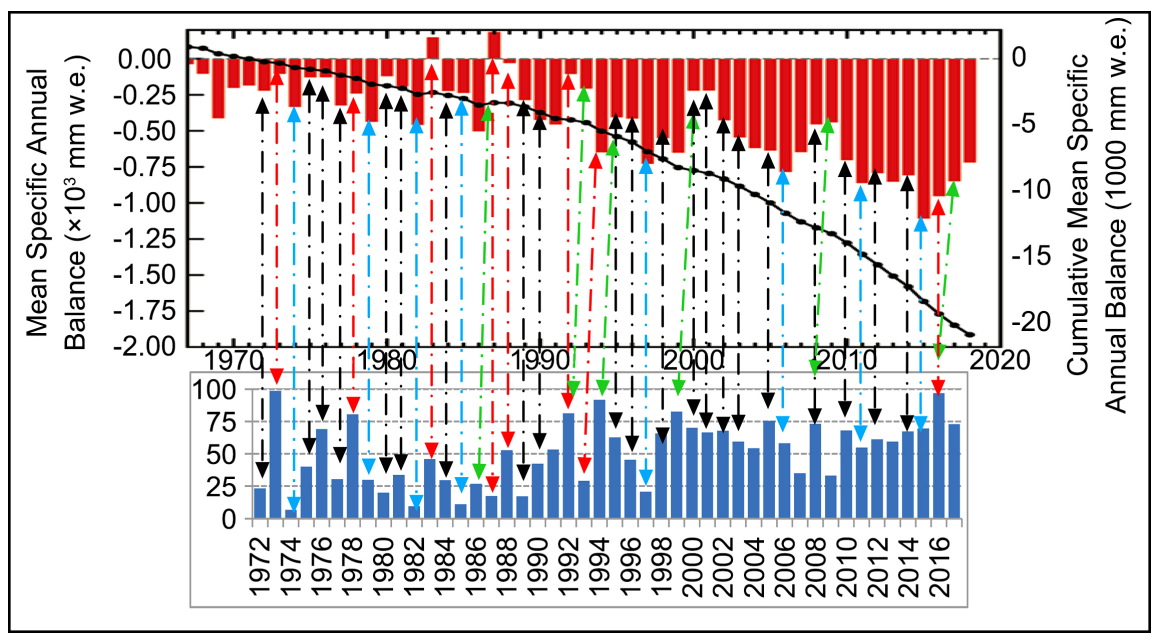

Figure 9. Upper red bars graph shows year vise mass balance of WGMS 37 Alpine reference glaciers since 1968, along with total mass loss over time (black line). Credit: State of the Climate in 2018. Bull. Amer. Meteor. Soc. The blue bar graph (1972-1997) is flood water drained to Arabian sea and somewhat equivalent to that rushed to, absorbed and caught standing in flooded area and ultimately evaporated to feed to GAC mainly in this and to the next year, particularly when its quantity is large. This is not exactly same as Component Rivers have different ratio of the flow caught for evaporate and that drained to Arabian Sea. 1998 onward is the total flow [17]. From above mutual comparison it is clear that glaciers melting rate closely (about $80 \%$ - 90\%) responds to cooling of GAC fed by Pak.-Floods. Red markers show higher cooling and less melting with green marker showing effect in the next year too and reverse for blue, while black show relative instant response.

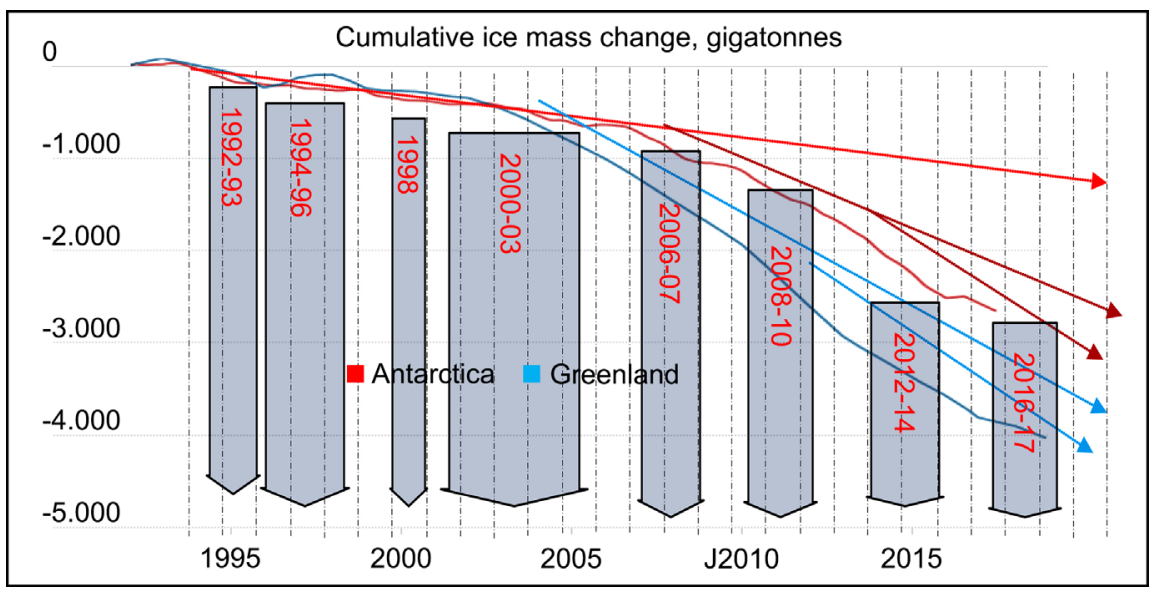

Figure 10. Antarctica and Greenland are now losing ice six times faster than in 1990s [22]. Antarctica ice melting rate reduction response to cooling of GAC fed by the Floods in Pakistan (marked with years in red numbers) is about $80 \%-85 \%$. Time vise melting rate has Exponential rise. 


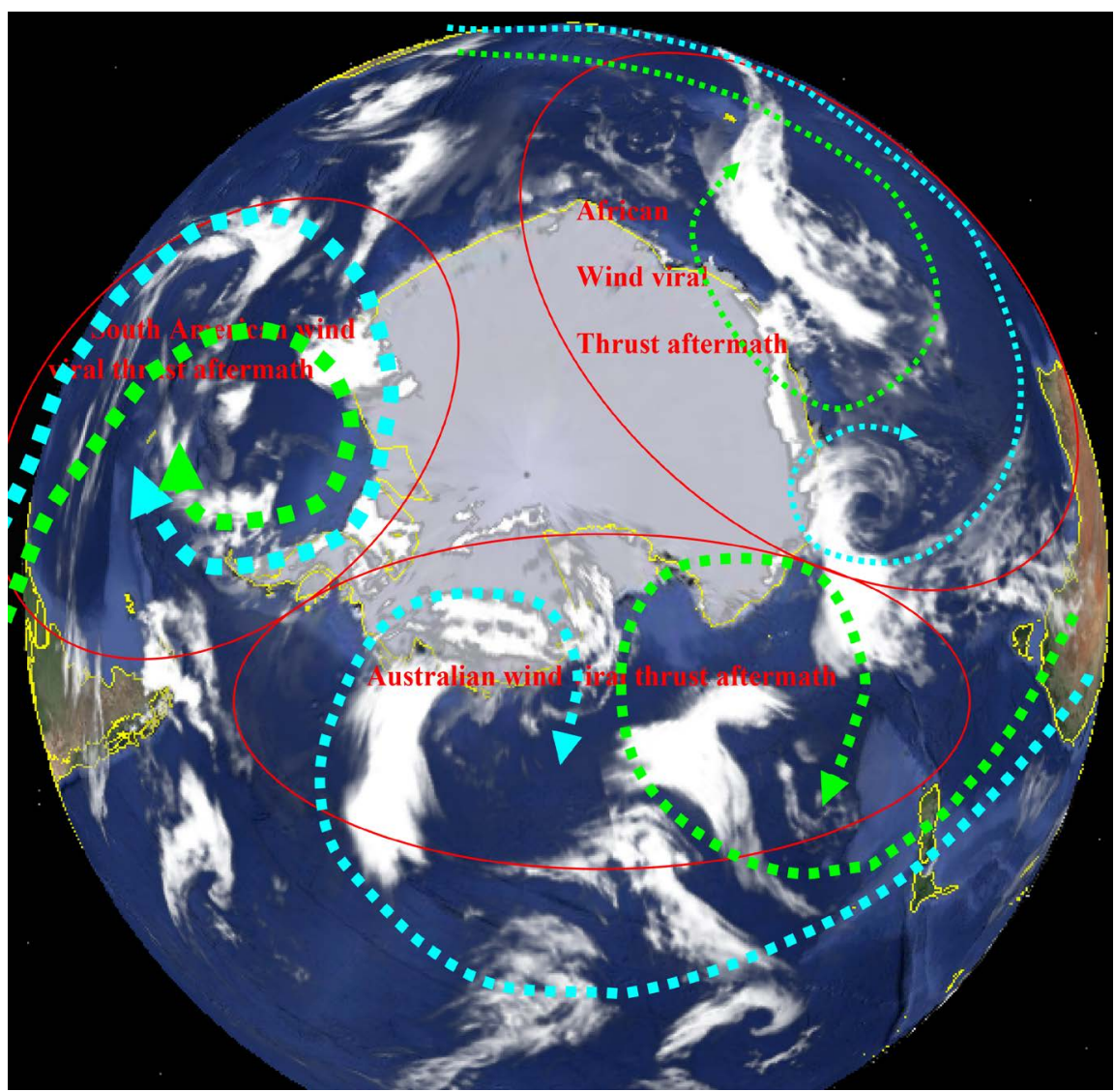

Figure 11. Antarctica ice heap under attack by wind viral blasts from South American, African and Australian Continents motivated by IBWT through its nurtured Global Heat Contents and Temperature and directly by offshoots of its water vapors deprived Indian air wheels. The cyan d0tted lines show the route and intensity of fired wind viral attacks on Antarctica by 3 continents.

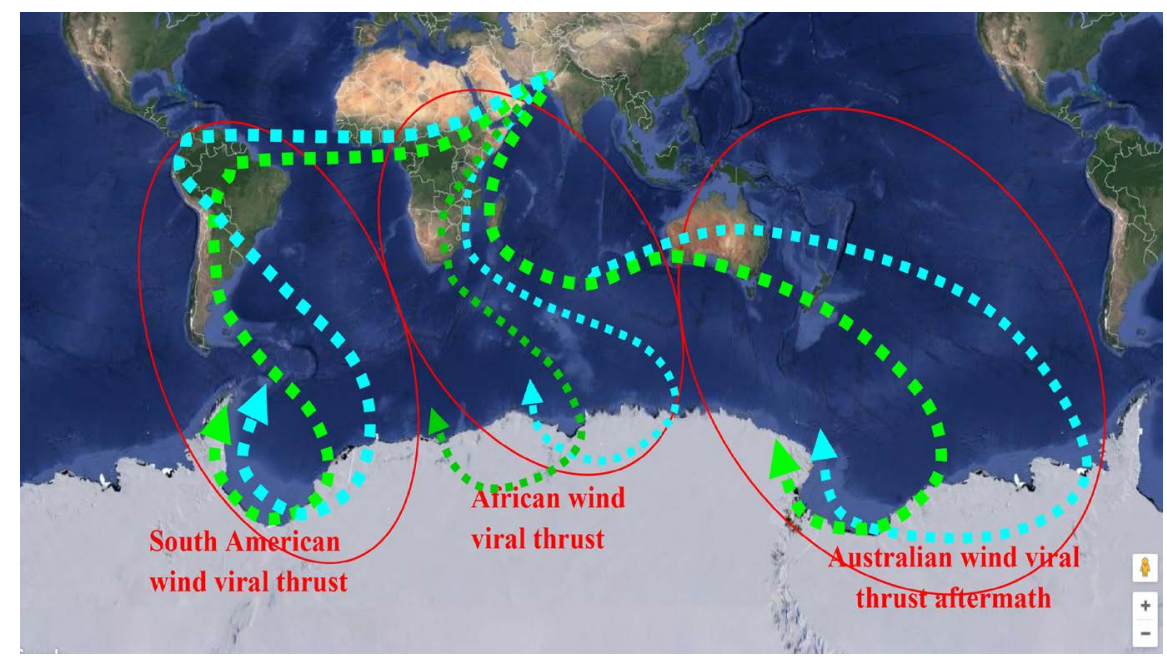

Figure 12. Antarctica ice heap under attack by wind viral blasts from South American, African and Australian Continents motivated by IBWT through its nurtured Global Heat Contents and Temperature and directly by offshoots of its water vapors deprived Indian air wheels, with their possible tracks shown above. 
is through Australia (Figure 11, Figure 12), while Greenland is under indirect attack from aftermath and offshoots of NAH and European bound wind from the Northern Pacific (Figure 2). Figure 10 shows the trends of their ice melting [25]. The rate of melting ice is increasing with time at a very fast rate; much faster for Greenland than Antarctica as it is prone to severer multiple direct attacks by NAH tail windgusts sponsored by IBWT through water deprived IAW and European bound wind from the Northern Pacific. The possible tracks of direct attack by offshoots of water vapors deprived IAW on Antarctica ice heap as wind viral blasts from South America, Africa and Australia motivated by IBWT is shown in Figure 11 and Figure 12 over and above through its nurtured GHT. The water Feed to IAW by Pakistani floods, a part recoded by WAPDA as drained to Arabian Sea and a part by [17] show prominent reduction (80\% 90\% matching) in Alpine and Antarctica ice melting rates (Figure 9, Figure 10). This proves that reduction of Global temperature by IBWT Reversal will carry on reducing this sublimation rate and the time will soon come when it starts their buildup, if WEPC buildup carried on as per recommendations given at the end.

\section{Revised Pakistan Irrigation Role}

In view of 105 days long crucial activity in place of 3 month or 90 days peak duration of air wheels generation as per Para 4.1 above of NAH 100 Years Frequency given in [11], the role of Pakistan Irrigation Supply as given in [7] [8] [9] needs up-gradation along with up gradation of assumptions too made in [7] [8] [9] [10].

1) The stated, 3 month duration of air wheel generation and propagation to Atlantic and Indian Oceans and fourth month totally to Indian Ocean in a year [7] [8] is practically found to be for 3.5 month as per paragraphs 4.1 above and Figure 7 and a month respectively (Upgraded).

2) The water evaporation rate assumed [7] [8] to be constant throughout the year is not logical. In the hot and windy months, rolling of air wheel with excessive water available in the presence of extra water needing crops of rice and sugarcane, it may not be less than 1.3 times than that of winter. Thus 39 MAF water annual usages, the winter usage will be $2.71 \mathrm{MAF}$ per month for 4 cold months and 3.52 MAF per month for 8 hot months as estimated below.

$$
4 \mathrm{x}+8{ }^{*} 1.3{ }^{*} \mathrm{x}=39 \text {, Or } 14.4 \mathrm{x}=39 \text {, Or } \mathrm{x}=2.708 \text { or } 2.71 \text { and }
$$

$1.3 \mathrm{x}=3.523$ or 3.52

Thus $3.52 * 3.5=12.32 \mathrm{MAF}$ is the evaporated in 3.5 months. (Upgraded)

3) One fourth of the air wheels are assumed to go to Indian Oceans and $3 / 4$ to Atlantic. Thus 9.24 MAF flow to Atlantic and 3.08 MAF to Indian Ocean bound air wheels, while in the next month (01 to 30th November) the entire monthly flow i.e. 3.52 MAF is towards Indian Ocean dragged by LSB for the activity under study. Hence 6.6 MAF is the share of Indian Ocean and 9.24 MAF that of Atlantic (Upgraded). 
4) The off and on movement of air wheel in remaining 126 active days (Figure 7) as stated above in section 4.2 was not accounted for in [7] [8], which is now also accounted for heat transport calculation. In peak 3.5 months, the average frequency of storms (depressions) is almost 59, while for remaining 126 days, it is about 7. Thus for accounting the total only through the active 3.5 month, their heat transportability may be 1.14 at least for Atlantic Ocean portions as estimated below.

Heat Transportability or

Water Evaporation Capability $=(105 \times 59+126 \times 7) /(105 \times 59)=1.1424$ (Upgraded).

5) Thus water usage in evaporation by Atlantic bound air wheels $=9.24 \times$ $1.1424=10.53 \mathrm{MAF}$ (Upgraded).

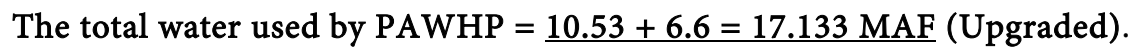

6) As in [7] [8], African part of air wheels is to travel 11,000 km till mid of Atlantic Ocean and Indian Ocean part is to travel 12,000 km up till the southern westerly route for their heat transmission activity (Retained).

7) As in [7] [8], the rolling speed of air wheels is $1 / 2$ of the slipping or $1 / 3$ of the total speed and thus distance covered by PAWHP is $1 / 3$ (Retained).

8) In [7] [8] rolling and slipping speeds of air wheel in India and Pakistan were taken at par with those going through Africa. These are not logical, when monsoons and easterlies are much prominent booster of slipping speeds of RCT generated African bound air wheel. Here in India and Pakistan, the two may be equal and hence $1 / 3$ in this case will be only $1 / 2$ (Upgraded).

9) As in [7] [8] the Indian Ocean part heat transport efficiency is taken $25 \%$ as compared to African part, being on the water surface with low temperature environment than the African desert with high temperature environment, with the more driving temperature difference (Retained).

10) Heat transport capability in India and Pakistan was taken at par with Africa, which is not logical, as driving temperature difference is large at African track than that at India and Pakistan. It is now taken as 0.6 times that of Africa (Upgraded).

11) Diameter $D$ of the air wheel $=$ height of cold layer/troposphere $=10 \mathrm{Km}$ and the Circumference of air wheel $=\pi^{\star} \mathrm{D}=\pi^{\star} 10=31.42 \mathrm{Km}$ (Retained).

12) As in [7] [8], the slipping part role in heat transport is neglected to cover up any deficiency in rolling part of air wheels (Retained).

13) In [7] [8], the rolling/slipping distance were taken equal both for India and Pakistan as $0-300 \mathrm{Km}$ (150 Km average), which is not logical. The Indian irrigated area by this IBWT diverted water is $0-500 \mathrm{Km}$ (average $250 \mathrm{Km}$ ) from the precipitation worthy mountains on its north, while in Southern Pakistan it is between 600 to $1200 \mathrm{Km}$, i.e. on average $900 \mathrm{Km}$ in southern Pakistan. The water irrigation of the rest of Pakistan has area of use between $80 \mathrm{~km}$ to $600 \mathrm{Km}$, i.e. on average $340 \mathrm{Km}$ (Upgraded).

14) Only the precipitation part is taken into account and component of heat 
transport through latent heat of sublimation of ice arrived from snow fall and hails storms is neglected to compensate any overestimation, although in the local WEPC of Northern Pakistan, snowfall throughout the year is about 1/4 times that of rainfall (Retained).

\subsection{GHT Export to Outer Space by Pakistani WEPC/PAWHP (9-a Part)}

As per global energy budget [23], the capabilities of main heat transporting components of saturated and semi precipitated Pakistani PAWHP evaluated with respect to assumed 100 units of Sun radiation and $24 \%$ of Latent heat of evaporation is $75 \%$ over and above the dry one [7] [8]. Thus total heat Emission as compared to latent heat of evaporation $=75 / 24=3.125$ times.

\subsubsection{GHT Export by Atlantic Ocean Part}

This is estimated as follows.

Weight of 10.53 MAF water $=10.53 \times 1233.482 \times 10^{6} \mathrm{M}^{3}$

$$
=12988.57 \times 10^{6} \mathrm{M}^{3}=12988.57 \times 10^{12} \mathrm{KG}
$$

Latent heat of water $/ \mathrm{KG}=2265 \mathrm{KJ} / \mathrm{Kg}$

Total Latent heat of $10.53 \mathrm{MAF}=29.42 \times 10^{18} \mathrm{~J}$

Total heat transported per wheel turn $=29.42 \times 75 / 24=91.935 \times 10^{18} \mathrm{~J}$

Total heat transported per wheel turn/MAF $=91.935 \times 10^{18} \mathrm{~J} / 10.53=8.73 \times 10^{18} \mathrm{~J}$

The track over Africa and Middle of Atlantic $=11,000 \mathrm{Km}$

Track traced by air wheels through rolling $=11,000 / 3=3667 \mathrm{Km}$

Number of cycles/turns of air wheel in traversing the whole track $=3667 / 31.42$ $=117$

Thus heat transferred to space $=91.935 \times 10^{18} \times 117=10.756 \mathrm{ZJ}$

\subsubsection{Heat Export by Indian Ocean Part}

Total heat transported per wheel turn with $25 \%$ efficiency $=8.73 \times 6.6 \times 0.25 \times$ $10^{18}=14.4 \times 10^{18} \mathrm{~J}$

The track over African eastern coast and Indian Ocean $=12,000 \mathrm{Km}$ and track traced by air wheels $=12,000 / 3=4000 \mathrm{Km}$

Number of cycles/turns of air wheel in traversing the track $=4000 / 31.42=127$

Thus heat transferred to space $=14.4 \times 10^{18} \times 127=1.829 \mathrm{ZJ}$

Thus Indian Ocean alone has been deprived of removing $1.829 \mathrm{ZJ}$,

While the rest of world by $10.756 \mathrm{ZJ}$

Thus total heat export potential of PAWHP $=10.756+1.829=12.585 \mathrm{ZJ}$.

\subsubsection{IBWT Role Analysis}

The average distance traveled by vapors of PAWHP for 39 MAF in India on plan area, where it is being used is nearly $0-500 \mathrm{Km}$ from mountainous precipitation area, i.e. average $250 \mathrm{Km}$ and it may have air wheel cycles $250 / 31.42 / 2=4$ cycles, assuming equal slipping and rolling speeds.

Thus heat transport by Indian used of 17.13 MAF water is

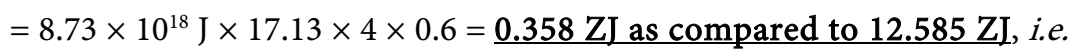


it is $\mathbf{3 5}$ times less than that of IBWT reversion state.

The total heat transported by India per year through IBWT gained water = $0.358 / 17.13 \times 39=0.815 \mathrm{ZJ}$ per year.

The use of rest of this water $(39-17.13=21.87$ MAF $)$ in 8.5 months in Pakis$\tan$ in local cycle is in area which is about $600 \mathrm{Km}$ to $1200 \mathrm{Km}$ from mountains precipitation area, i.e. $900 \mathrm{Km}$ on average.

This has $900 / 31.42 / 2=14.4$ cycles before precipitation.

Thus heat dissipation by $39-17.13=21.87 \mathrm{MAF}$ is

$=8.73 \times 10^{18} \mathrm{~J} \times 21.87 \times 14.4 \times 0.6=1.65 \mathrm{ZJ}$.

Hence, the total heat transport by Sothern Pakistan per year $=12.585+1.65$

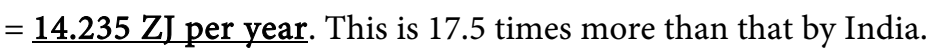

The net loss to Global heat dissipation $=14.235-0.815$ (Indian recovery)

$=\underline{13.42 \mathrm{ZJ} \text { per year. }}$.

The net gain in rate of average Global heat rise after $1973=16.48-2.0=$ $14.48 \mathrm{ZJ} / \mathrm{yr}$.

Thus share of IBWT in Global Heat gain rate is $13.42 / 16.48=81.4 \%$

And in the increase above 1960 status is $13.42 / 14.48=92.7 \%$

This means, that IBWT is almost only and sole culprit behind the extraordinary huge rise of GHT. Even without RCT desert generated air wheels, the role of IBWT water irrigation with respect to GHT is not same in India and Pakistan. Difference is due to distance of irrigated area from mountains precipitation location.

\subsection{Chulistan and Thar Contribution Potential (9-c Part)}

The contribution of irrigation of Chulistan and Thar towards GHT is absolutely similar as that of irrigation of Southern Pakistan. In [8] [9], the heat pumping potentials of Chulistan and Thar and that of Southern Pakistan were estimated as10.4133 ZJ and 9.3912 ZJ respectively. Thus revised contribution of irrigation of Chulistan and Thar will be $=14.235 / 9.3912 \times 10.4133=15.78 \mathrm{ZJ}$.

\subsection{Northern Pakistan Contribution Potential (9-b Part)}

The possible water circulation by the Pakistani resources with respect to GHT control is 393 MAF [8] misguided (to be clarified in forthcoming article) to be only $142 \mathrm{MAF}$ at present.

About 43.244 MAF water has to be shifted to Thar and Chulistan for their irrigation and its contribution [7] [8] estimate is given above.

Thus total Heat of $(393-43.244=) 349.756$ MAF per roll of an air wheel. $=$ $8.73 \times 349.756 \times 0.6 \times 10^{18}=1.832 \mathrm{ZJ}$.

The distance traveled on plan area is nearly $80-600 \mathrm{Km}$, i.e. average $340 \mathrm{Km}$ and it may have $340 / 31.42 / 2=5.4$ cycles.

Thus total heat transported $=5.4 \times 1.832 \mathrm{ZJ}=9.893 \mathrm{ZJ}$.

The above revised estimates are shown in the following table for mutual comparison. 
IBWT reversion heat transport capability $=14.235 \mathrm{ZJ}$.

Heat transport capability of rest of Pakistan $=9.893+15.78=25.673 \mathrm{ZJ}$.

\section{Revised GHT Disasters Rollback Capability of Pakistan}

The annual Global heat buildups estimated as per global heat graphs [2] [3] [4], are $7.1,8.75,10.1$ and in [1] is 16.48 ZJ. Thus IBWT seems to be the only major responsible with heat flow Obstruction of $13.42 \mathrm{ZJ}$. With respect to $16.48 \mathrm{ZJ} /$ year global heat buildup, the IBWT has the major role (81.4\%) accompanied by the other contributor; that are most probably continuous extraordinary explosive use in warfare, extraordinary huge wildfires like that of California 2017-2018 wildfire [15], fossil fuels usage for energy demands and numerous volcanic eruptions, all within remaining $18.6 \%$ contribution, excluding the heat forcing its way to troposphere through instant WEPC in from of the aftermath of these hazards as pointed out in [15] for 2017-2018 California wildfires and that pointed out for Brazilian 2019 and Australian 2019/2020 wildfires.

Table 3 shows the rate of global heat rise of all the above stated four estimates and also the estimated possible heat outflow rate by the 3 parts of Pakistani WEPC, showing potentials of part $a$, parts $a+b$ and all the 3 parts, i.e. $a+b+c$. Table 3 also show the approximate time to restore the safe environmental status given by $\mathrm{X} * \mathrm{Y} /(\mathrm{Z}-\mathrm{X})$. Here $\mathrm{X}$ is heat annual buildup rate, $\mathrm{Y}$ is the time duration of rate estimated + its gap before 2021 with further 10 years minimum period for mobilization of the resettling system and $\mathrm{Z}$ is the additional heat outflow rate by different groups of Pakistan's WEPC components given in Table 2 above. From comparison of heat in and possible outflow, it seems that for blocking and reversal of the growth of global heat and its all Tribe and control the brutalities of USA bound North Atlantic Hurricanes and their Tribes, mobilization of all the 3 outflow parts of Pakistan WEPC is extremely and immediately vital along with strict control on at least all the following 3 huge and critical GHT, GHG, Soot and pollution feeders.

1) Fossil Fuels Use in energy demands

2) Explosive use in warfare and

3) Jungle fires.

Table 2. Pakistan's global heat transport potentials.

\begin{tabular}{cccc}
\hline & & \multicolumn{2}{c}{ Heat Transport Potential } \\
\cline { 3 - 4 } S/No. & Pakistani Heat Transporting component & $\begin{array}{c}\text { Old } \\
\text { Estimates }\end{array}$ & $\begin{array}{c}\text { Revised } \\
\text { Estimates }\end{array}$ \\
\hline a & Heat Outflow Rate by IBWT reversion & $9.024 \mathrm{ZJ}$ & $14.235 \mathrm{ZJ}$ \\
b & Heat Outflow Rate by Northern Pakistani system & $5.46 \mathrm{ZJ}$ & $9.893 \mathrm{ZJ}$ \\
c & Heat Outflow Rate by Chulistan and Thar irrigation & $10.01 \mathrm{ZJ}$ & $15.78 \mathrm{ZJ}$ \\
& Heat Outflow Rate by sum of S/No. a, b; $(\mathrm{a}+\mathrm{b})$. & $14.484 \mathrm{ZJ}$ & $24.128 \mathrm{ZJ}$ \\
& Heat Outflow Rate by sum of S/No. a, b, c; $(\mathrm{a}+\mathrm{b}+\mathrm{c})$. & $24.494 \approx 24.5 \mathrm{ZJ}$ & $39.908 \approx 40.0 \mathrm{ZJ}$ \\
\hline
\end{tabular}


Table 3. Global heat input and the time required for pre-1960 status restoration by mobilizing pakistan's potentials.

\begin{tabular}{|c|c|c|c|c|c|}
\hline \multicolumn{2}{|l|}{ Figures } & Est. 1 & Est. 2 & Est. 3 & Est. 4 \\
\hline \multicolumn{2}{|c|}{$\mathrm{X}=$ Annual Heat Input rate in $\mathrm{ZJ}$} & 7.1 & 8.75 & 10.1 & 16.48 \\
\hline \multicolumn{2}{|c|}{$\begin{array}{l}\mathrm{Y}=\text { Build up in years (duration of rate estimate }+ \text { Gap before } \\
\quad 2021+10 \text { years for resettling system mobilization) }\end{array}$} & $35+13+10=58$ & $40+9+10=59$ & $41+13+10=64$ & $43+7+10=60$ \\
\hline Global Heat Reducing Components & $Z=$ Outflow of Heat ZJ & \multicolumn{4}{|c|}{ Years required for restoration of pre 1960 status } \\
\hline IBWT Reversal, S/No. $\underline{\mathbf{a}}$, Table 2 & 14.235 & 58 & 94 & 156 & Not $^{*}$ \\
\hline $\begin{array}{l}\text { As above }+ \text { Northern Pakistan system } \\
\text { S/No. } \underline{\boldsymbol{a}+\boldsymbol{b}} \text {, Table } 2\end{array}$ & 24.128 & 24 & 34 & 46 & 129 \\
\hline $\begin{array}{l}\text { As above }+ \text { Thar \& Chulistan irrigation, } \\
\text { S/No. } \underline{a+b+c} \text {, Table } 2\end{array}$ & 39.9 & 13 & 17 & 22 & 42 \\
\hline
\end{tabular}

It can be seen from this that for more early restoration of 1960 environmental and GHT status, along with the above, some more WEPC implementation sites needs to be explored in tropical zones like Africa, Australia, South and North America.

Thus the revised estimates with optimum usage of Pakistan's resources minimum 42 years will take to restore the pre-IBWT environmental and GHT status.

\section{Flow Budget and Capability of Pakistan Water Cycle}

The components of Pakistan's water cycle and its flow budgets are shown in table and Figure 13. The two components parts corresponding to (9-a) and (9-c) of GAC as stated in section 3 above and shown on right side are most efficient, to work with 39 and 43 MAF flows, transmit 14.235 ZJ and 15.78 ZJ Global Heat to Troposphere and 17.13 and 19 MAF water respectively to Global PAWHP, while balance 21.87 and $24 \mathrm{MAF}$ to rain in western India and mainly in Himachal Pradesh and Uttara Khand from November to June as per largest wind cycle No. 4 of Pakistan [9]. These two parts are unique in rolling their air wheels in at least 117 and 127 cycles as estimated in subsections 7.1.1 and 7.1.2 above. The component part corresponding to (9-b) of GAC is a bit less efficient using 100 MAF flow and pumping out $9.893 \mathrm{ZJ}$ heat. However, like the other two parts it is unique in the World in different sense. It can regenerate about 300 - 350 MAF additional flow by local re-recycling having water flow cycle of about 3 month with unique topography in a unique geophysical location in the Globe for its heat transportability in a few air cycles coping with irrigation and hydro power needs of Pakistan. This part is also promoter of (9-c) of GAC by enabling water supply for it. The flow input and output are $100 \mathrm{MAF}$ each including saving of aquifer recharge of 7 MAF per year. Long over the year's or decadal storage of 340 - $430 \mathrm{MAF}$ and underground water pumping will provide multi years human flow regulation to cope with the natural flow fluctuations in Monsoons and glaciers sublimations. This will also boost the glaciers buildup with GHT decline 


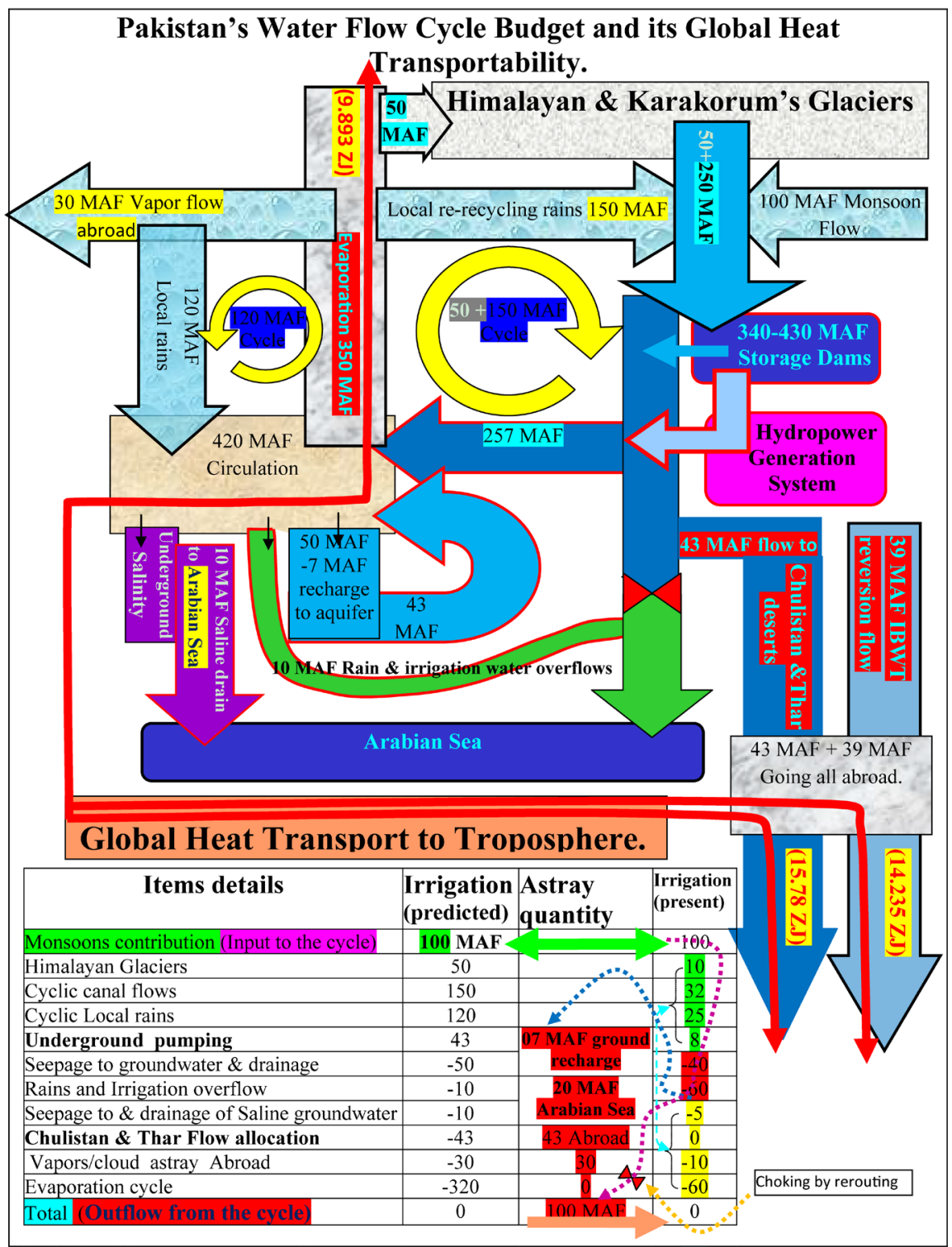

Figure 13. Above are the components of Pakistan water cycle showing flows budget also detailed in the above table. The net input \& outputs are $100 \mathrm{MAF}$ each. The storage dams and underground aquifers are human regulated flows reserves + monsoon \& Glaciers as natural guided flows. A 3 month cycle regenerates $\approx 350$ MAF flow.

and the added flow circulation and better environment with increased frequency of moderate rains throughout the year not only in Pakistan, but also in all the surrounding counties especially the India. This will need comprehensive development of

1) Storage dams for irrigation supply decadal regulation, hydropower generation, floods controls and aquaculture promotion.

2) Flood diversion channels to divert the floods flow to storage dams.

3) Irrigation system.

4) Saline Drainage system to drain out the salinity and unsuitable salts to enable the saline land for agriculture. 
5) Recycling Drainage to reuse the rains and irrigation surplus water in downstream irrigation and suitable portion to sea to promote sea aquaculture upstream flow.

The last two must be the separate drains as shown above and recycling drain may even use river channel. The last column in table above shows the present flow pattern. The flows highlighted green transform to that as yellow, while the 100 MAF input is wasted by flood flow, 60\% - 65\% to Arabian Sea and about 35$40 \%$ forced to absorbed by the land through retention in flooded land and ponds. This needs to be stored in dams and then recycled through irrigation of vast area, evaporated and absorbed systematically in proportion of 320/60 and not let it go directly to Arabian Sea (blocked red line), but through drainage of irrigation seepage to salinity (blue line) and any willful prioritized need like aquaculture transport from sea to dams and mangrove promotions.

\section{Findings, New Paradigms and Results}

1) RCT deserts and Sun radiations generating air wheels trains, the July-October gap in the Pakistani coastal winds flow, the gate for these air wheels to roll westward, gap in the Indian coastal winds before their winter direction reversal to allow Monsoons to boost the kinetic energy of these air wheels, Southern Pakistan supplier of water vapors as Freon of GAC through its irrigation system, Easterlies express trains as transcontinental carriers of these air wheels, Africa as largest global heat source otherwise distributing it to the whole world in absence of air wheels' water vapors saturation in Pakistan, the African western coastal wind toppling and directing major part of RCT air wheel into NAH and steering them to USA and Europe, all the Oceans as huge heat capacitors and water evaporation facilitators and hurricanes categorizer (Figure 6) [18] [19], polar and Glaciers ice, various mountains ridges and valley's patterns and land topography as guides for wind and clouds and many other components with Troposphere form a Devine manufactured, unique and ideal GAC set in operation, all out of human reach, except its control switch, the optimum irrigation in Pakistan, is a new Paradigm (NPD).

2) Global Heat troposphere transportability by RCT air wheels based GAC without water vapors is only $11.76 \%$, while with maximum water vapors only from Pakistan, it is $100 \%$.

3) The kinetic energy of Indian Monsoons air blast speeds up the movement of air wheels and resulting hurricanes. The more sever is this push, more speed, deep penetration and vast brutality will be that of NAH in the absence of optimum irrigation of Pakistan.

4) The huge rate of GHT rise since 1973 is due to blockage of its natural dissipation through divinely created GAC by continuous bleeding of its Freon, the water by its IBWT diversion since 1971/1972. Since then, Earth Globe and its all living inhabitants are under continuously increasing multipronged attacks of above stated devils and dragons (NPD). 
5) At present, Category 5 hurricanes can happen over Atlantic Ocean if its surface temperature is above $82^{\circ} \mathrm{F}$ and Category 4 can happen if it is $81^{\circ} \mathrm{F}$ [18], while over the Pacific; it may be $81^{\circ}$ and $80^{\circ} \mathrm{F}$ respectively [19] due to long distance and long contact time in case of Pacific Ocean. These temperature limits will soon be crossed with IBWT continuous feed to GHT and very soon such limits would have to be defined for new categories 6 and 7 Hurricanes (a most Critical Warming).

6) About $807 \mathrm{ZJ}$ heat has been heaped on earth globe, while by the next 10 (resettling system mobilization period) years it will become $973 \mathrm{ZJ}$, mostly in Oceans, extremely disastrous both for marine and land life along with multiple disasters in aqua and agriculture.

7) Huge continuously rising polar and glaciers ice sublimation rate and recent huge differential heating of Oceans are mainly the aftermath of tragic IBWT implementation.

8) Southern Pakistan irrigation system was pumping out 14.235 ZJ Global Heat to the Troposphere through above stated GAC till 1970 when IBWT implementation diverted its all 39 MAF water (the Freon of GAC) annually to India. In India, its GHC dissipation capability reduced from 14.235 ZJ to only $0.815 \mathrm{ZJ}$, thus a too heavy dose of $13.42 \mathrm{ZJ}$ heat per year was calmly dripped into the vanes of Earth Globe. Thus, 39 MAF water back reversion to Pakistan is an extreme Global Emergency measure; absolutely needed for Control of further dangerous growth in Environmental catastrophes and Global calamities.

9) Along with IBWT reversal, about 9.893 ZJ Global Heat dissipation potential of Northern Pakistan (sec. 9 above) through optimum and comprehensive water storage and irrigation system development is immediately needed for the Earth Globe to fizzle out 973 ZJ heat.

10) If the joint venture of above Nos. 8 and 9 could be fully mobilized by year 2032, it will take about 129 years to disperse the 973 ZJ heap of Global.

11) Chulistan, Thar and Thal deserts irrigation has the potential to dissipate further $15.78 \mathrm{ZJ}$ Global Heat per year and it is also needed to join the above stated joint venture. With mobilization of this part too by 2032, the above stated 129 years will reduce to 42 years.

12) Large Global Heat Contents and highly elevated Global Temperature are main reasons behind all the attacks of Huge Wildfires, Wind and Snow Storms, Hurricanes, extremely Heavy Rains, Floods, Heat Waves, Volcanic Eruptions and Epidemics, huge sublimation rate of polar and glacier ice etc. throughout the entire World. With the growth of GHT, all these calamities will grow up exponentially through their mutually sustained chain reaction. A recent example is the record breaking self-supporting Australian wildfire, resulting heat waves, record breaking rains and snow storms throughout the Earth Globe.

13) North Atlantic Hurricanes take birth only in Rajasthan, Chulistan and Thar (RCT) deserts of Indian Subcontinent in form of vertically rolling air 
wheels generated by Sun radiations over and above the GHT baseline, rolled back westward by the earth polar rotation and push further by Indian Monsoon (NPD).

14) Multiple NAH at a time and those of diameter more than $20 \mathrm{~km}$. are initiated only in $1^{\text {st }}$ Chulistan, $2^{\text {nd }}$ Rajasthan and $3^{\text {rd }}$ Thar agitated by GHT baseline in 1 - 3 IAW trains on 3 tracks from north to south respectively (NPD).

15) The Indian Air Wheels can only be saturated by the water vapors in southern Pakistan.

16) The lime Share of Indians air wheels is forced towards USA and remaining lone alone may only generate typhoon or tornado land falling in Fareast, if these do not fizzle out on the way. This differentiates the types and nature of Japan's and USA landfalls (NPD).

17) The GHT is attacking NAH through its following six fronts; all in queue one after the other, all in continuous and simultaneous action by raising energy

a) and frequency by direct boosting of Indian air wheels (IAW).

b) of IAW through its boosted push by boosted monsoons.

c) of IAW through GHT boosted Easterlies.

d) of IAW through GHT boosted African heat energy.

e) of IAW/Hurricanes by GHT boosted African west coastal wind push during their toppling through South American reverted easterlies and IAW.

f) and category of Hurricanes by GHT boosted Atlantic Ocean Surface temperature.

Thus, higher is the Global Heat Contents, particularly the Global Temperature, higher is the numbers of RCT desert generated air wheels, higher is their kinetic energy and higher is the speed, frequency, intensity, deep penetration, brutality and vast devastation of resulting hurricanes if not fully blended with water vapors on their way in Pakistan (NPD).

18) The unscientific, unnatural, illogical, pervasive, disastrous and horrible move of IBWT in 1960 is continuously blasting million of Corona like invisible and silent bombs on the entire Globe without brake; a terrible gift from its sponsors, the World Bank, USA, UK, Australia etc. They should take the responsibly of their misadventure, review and correct their unscientific moves and motivate the entire world at top emergency to contribute to the development of all the required infrastructures under UNO management to mobilize joint ventures referred to at No. 8, 9 and 10 above.

19) Southern Pakistan can provide the required water vapors if IBWT is reversed along with mobilizing other 2 parts (9-b \& 9-c) of GAC for the most wanted Global Heat dissipation role and steer the process from its disastrous role to its beneficial role. Through energy dissipation/transportation, this will also surely moderate NAH. Its absence since 1970 has boosted extraordinarily their severity and brutality as pointed out by 15 aspects in [10].

20) The three portion of Pakistan water evaporation and precipitation cycle (WEPC), if mobilized properly, completely and immediately are able to success- 
fully control and rollback the high speed rising Global Heating and all its tribe to pre-1960 safe status in about 42 years. Thereafter, it will take care of all the ever increasing abnormal and unavoidable inputs perhaps for centuries. This needs optimum development of infrastructure for seasonally available water storage, irrigation, drainage (of unwanted rains and underground water) and hydro power generation systems by the International Community under UNO management.

21) The heap of Global heat contents in Oceans is not asleep. It and its temperature are enforcing the brutal Categories to the wind storm and hurricanes along with terrible devastation of marine culture.

22) The earth Globe is small enough for transcontinental and across the Globe multiple propagation of environmental affects.

\section{Recommendations}

\section{UNO, USA, UK and the World Bank should}

1) Immediately intervene for reversion of Indus Basin Water Treaty and release of $39 \mathrm{MAF}$ water to Pakistan to stop further rise of the extremely dangerous GHC.

2) Mobilize all the 3 parts of WEPC of Pakistan i.e. mobilize a comprehensive drive for construction of all the possible water storage dams, irrigation, drainage, hydropower generation systems and land development for irrigation and optimally manage its all functionalities for reestablishing the Global safe environment.

3) Collect the funds for this purpose from all the countries proportionate to both their usage and production of fossil fuels including that of last 50 years along with all other heat, $\mathrm{CO}_{2}$ and pollution inputs, like usage of explosives, nuclear and missile tests, wild forest fires, satellites launches etc.

4) Locate also, the other sites globally and get designed and developed all the required infrastructures of WEPC systematic further promotion.

5) Enforce the safety measures to avoid and immediate control on all jungle fires.

6) Promote hydro, solar, wind and Oceanic current sources of power production throughout the world, particularly that of Pakistan with huge such multiple potentials.

7) Penalize financially all the culprits in materialization of unscientific, unnatural IBWT and use it in activity at No. 2 above.

8) In view of the highly critical global situation, all the political, social, territorial obstructions/objections to this issue be overruled and sever and strict sanctions be imposed on non-cooperators.

9) The countries with no option for their power generation other than fossil fuels or least possible control on wildfire hazards may compensate their this unwanted input to the Global Environment through helping in development of those countries having heat and pollution free power production potential but 
with financial constraints to materialize it for Global environmental safety promotions.

10) Earliest reversion of IBWT must be ensured.

\section{Acknowledgements}

Author is highly thankful to all helpers, authors and the publishers whose information/data/graphs has been used directly or indirectly, modified or reset or reformatted for this and previous papers for sake of human and Global safety and welfare.

\section{Conflicts of Interest}

The author declares no conflicts of interest regarding the publication of this paper.

\section{References}

[1] Cheng, L.J., et al. (2017) Improved Estimates of Ocean Heat Content from 1960 to 2015. Science Advances, 3, e1601545. https://doi.org/10.1126/sciadv.1601545 http://advances.sciencemag.org/content/3/3/e1601545.full https://www.eurekalert.org/pub_releases/2017-03/ioap-ans031317.php

[2] Church, J.A., et al. (2011) Revisiting the Earth's Sea-Level and Energy Budgets from 1961 to 2008. Geographical Research Letters, 38, L18601.

https://www.skepticalscience.com/empirical-evidence-for-global-warming.htm https://doi.org/10.1029/2011GL048794

[3] Nuccitelli, et al. (2012) Comment on Ocean Heat Content and Earth's Radiation Imbalance. II. Relation to Climate Shifts.

https://skepticalscience.com/docs/Comment on DK12.pdf

[4] New Report: "Blowtorch"-Like Ocean Warming Advances Killer Seas, Shifts El Nino, Heats Hydrates. https://robertscribbler.com/tag/canfield-ocean

[5] Number of Reported Disasters by Type. https://ourworldindata.org/natural-disasters

[6] Ahmed, B. (2018) Who Takes Responsibility for the Climate Refugees? International Journal of Climate Change Strategies and Management, 10, 5-26. https://doi.org/10.1108/IJCCSM-10-2016-0149

[7] Nazeer, M.M. (2019) Mobilization of Water Cycle and Its Persian Air Wheel Heat Pump to Overcome Global Heating and Its Resulting Terrible Environmental Problems. Open Access Library Journal, 6, 1-17. https://doi.org/10.4236/oalib.1105445

[8] Nazeer, M.M. (2019) Major Culprit behind Horrible Steep Rise of Global Heat Contents and Temperature since 1973 and Its Blockage Strategy. International Journal of Scientific \& Engineering Research, 10, 789-807.

[9] Nazeer, M.M. (2019) Reversal of Terrible Global Heating and Its Gang through Unique and Complete Water Evaporation and Precipitation Cycle of Pakistan. International Journal of Scientific \& Engineering Research, 10, 1244-1263.

[10] Nazeer, M.M. (2019) North Atlantic Hurricanes Take Birth in India and Can Be Moderated Only in Pakistan by Reversion of Their Agitator, the Indus Basin Water Treaty of 1960. International Journal of Scientific \& Engineering Research, 10, 461-481. 
[11] 100 Years Frequency of North Atlantic Hurricanes, 2015 Hurricane Update with NASA's Dr Tim Hall.

https://insurancelinked.com/2015-hurricane-update-with-nasas-dr-tim-hall

[12] Nazeer, M.M. (1998) Naem Ather "Role of Earth Shape and Rotation in Generating and Tracking of Cyclones". Journal of Natural Science and Mathematics, 38, 217-227.

[13] Tracks of Tropical Cyclones. https://www.reddit.com/r/MapPorn/comments/1rdelj/tracks of tropical cyclones from 1842 to 2013

[14] Kelly, P., Ruby Leung, L., Balaguru, K. and Xu, W.W. (2019) Shape of Atlantic Tropical Cyclone Tracks and the Indian Monsoon. Geographical Research Letter, 46, 10,746-10,755.

[15] Nazeer, M.M. (2019) Tragic Aftermath of Californian Jungle Fire and Hawaiian Volcano Out-Burst, a Warning about Persistently Rising Global Warming, Resulting into High Rated Disaster's Chain. Open Access Library Journal, 6, e5118. https://doi.org/10.4236/oalib.1105118

[16] Major North Tropical Hurricanes, Our World in Data. https://ourworldindata.org/grapher/frequency-north-atlantic-hurricanes

[17] NASA and Dartmouth Observatory Given in. https://floodobservatory.colorado.edu/SiteDisplays/294.htm

[18] https://twitter.com/hausfath/status/908085403697111041

[19] https://climateanalytics.org/briefings/tropical-cyclones-impacts-the-link-to-climate -change-and-adaptation

[20] https://en.wikipedia.org/wiki/Sarasvati River

[21] https://en.wikipedia.org/wiki/Ghaggar-Hakra River

[22] Seasons Northern Hemisphere and Sun Declination; Climate Introduction. http://www.atmo.arizona.edu/students/courselinks/fall12/atmo336/lectures/sec4/sea sons.html

[23] Earth Globe Energy Budget. http://www.geocoops.com/uploads/2/4/5/3/24532387/1823846.jpg?804

[24] https://nsidc.org/cryosphere/glaciers/life-glacier.html

[25] https://www.theguardian.com/environment/2020/mar/11/polar-ice-caps-melting-si x-times-faster-than-in-1990s 
Abbreviations

\begin{tabular}{cccc}
\hline Abbreviations & Stands for & Abbreviations & Stands for \\
\hline GHC & Global Heat Contents & WEPC & $\begin{array}{c}\text { Water Evaporation \& } \\
\text { Precipitation Cycle }\end{array}$ \\
GHT & GHC \& Temperature & PAWHP & Persian Air Wheel Heat Pump \\
GHG & Green House Gasses & RCT & Rajasthan, Chulistan and Thar \\
GAC & Global Air Conditioner & SLB & Sea to land breeze \\
NAH & North Atlantic Hurricanes & LSB & Land to sea breeze \\
IBWT & Indus Basin water Treaty, 1960 & NPD & New Paradigm \\
MAF & Millions Acre Foot volume & WHO & World Health Organization \\
ZJ & Zeta Joules = 1021 Joules & IAW & Indian (RCT generated) air wheels \\
\hline
\end{tabular}

